\title{
Physical, Chemical and Mineral Properties of the Polonnaruwa Stones
}

\author{
Jamie Wallis \\ School of Mathematics, Cardiff University, Cardiff, UK \\ N. C. Wickramasinghe*, Daryl H. Wallis, Nori Miyake and M.K. Wallis \\ Buckingham Centre for Astrobiology, University of Buckingham, Buckingham, UK \\ Richard B. Hoover
Buckingham Centre for Astrobiology, University of Buckingham, Buckingham, UK
and
Athens State University, Athens, Alabama, USA \\ Anil Samaranayake and Keerthi Wickramarathne \\ Medical Research Institute, Colombo, Sri Lanka \\ Anthony Oldroyd \\ School of Earth and Ocean Sciences, Cardiff University, Cardiff, UK
}

\begin{abstract}
We report on the physical, chemical and mineral properties of a series of stone fragments recovered from the North Central Province of Sri Lanka following a witnessed fireball event on 29 December 2012. The stones exhibit highly porous poikilitic textures comprising of isotropic silica-rich/plagioclase-like hosts. Inclusions range in size and shape from mm-sized to smaller subangular grains frequently more fractured than the surrounding host and include ilmenite, olivine (fayalitic), quartz and accessory zircon. Bulk mineral compositions include accessory cristobalite, hercynite, anorthite, wuestite, albite, anorthoclase and the high pressure olivine polymorph wadsleyite, suggesting previous endurance of a shock pressure of $\sim 20 \mathrm{GPa}$. Further evidence of shock is confirmed by the conversion of all plagioclase to maskelynite. Here the infrared absorption spectra in the region $580 \mathrm{~cm}^{-1}$ to $380 \mathrm{~cm}^{-1}$ due to the $\mathrm{Si}-\mathrm{O}-\mathrm{Si}$ or $\mathrm{Si}-\mathrm{O}-\mathrm{Al}$ absorption band shows a partial shift in the peak at $380 \mathrm{~cm}^{-1}$ towards $480 \mathrm{~cm}^{-1}$ indicating an intermediate position between crystalline and amorphous phase. Host matrix chemical compositions vary between samples, but all are rich in $\mathrm{SiO}_{2}$. Silica-rich melts display a heterogeneous K-enrichment comparable to that reported in a range of non-terrestrial material from rare iron meteorites to LL chondritic breccias and Lunar granites. Bulk chemical compositions of plagioclase-like samples are comparable to reported data e.g. Miller Ranger 05035 (Lunar), while Si-rich samples accord well with mafic and felsic glasses reported in NWA 1664 (Howardite) as well as data for fusion crust present in a variety of meteoritic samples. Triple oxygen isotope results show $\Delta^{17} \mathrm{O}=-0.335$ with $\delta^{18} \mathrm{O}$ (\%o rel. SMOW) values of $17.816 \pm$ 0.100 and compare well with those of known CI chondrites and are within the range of CI-like (Meta-C) chondrites. Rare earth elemental abundances show a profound Europium anomaly of between 0.7 and 0.9 ppm while CI normalized REE patterns accord well with those of high potassium and high aluminium glasses found in lunar and 4 Vesta samples. Twoelement discrimination maps of $\mathrm{FeO}$ vs $\mathrm{SiO}_{2}, \mathrm{FeO}$ vs $\mathrm{TiO}_{2}, \mathrm{FeO}$ vs $\mathrm{Al}_{2} \mathrm{O}_{3}$ and $\mathrm{FeO}$ vs $\mathrm{Na}_{2} \mathrm{O}$ similarly match those of impact glasses present in lunar samples and remain within relatively close proximity of the KREEP component. Iridium levels of between $1-7 \mathrm{ppm}$, approximately $10^{4}$ times that of terrestrial crustal rocks, were detected in all samples.
\end{abstract}

Keywords: Polonnaruwa, Meteorites, Carbonaceous Meteorites, Fulgurites, Diatoms, Comets, Panspermia

* mail: ncwick@gmail.com, phone: +44-2920-752146 


\section{INTRODUCTION}

A potentially significant fireball event was reported during the last week of December 2012 in the skies above the Central Provinces of Sri Lanka. Several eyewitnesses in the North Central District of Polonnaruwa reported seeing a bright yellow fireball that turned green as it travelled across the sky at approximately 18:30 PM on December 29, 2012. The inferred NE to SW trajectory was determined from numerous eyewitness observations. The green fireball was reported to disintegrate with some luminescent fragments falling towards the ground in the village of Aralagonwila $\left(7^{\circ} 46^{\prime} 0^{\prime \prime} \mathrm{N}\right.$ and $\left.81^{\circ} 10^{\prime} 60^{\prime \prime} \mathrm{E}\right)$ about $35 \mathrm{~km}$ south of the ancient town of Polonnaruwa.

A number of stones were immediately recovered from the ground in the vicinity of Aralagonwila. Police records detail reports of low-level burn injuries from immediate contact with the fallen stones and subsequent reports of a strong aroma of tar or asphalt. Local police officials responded immediately by collecting samples and submitting them to the Medical Research Institute of the Ministry of Health in Colombo, Sri Lanka. Further stones were recovered by local farmers in the adjoining fields the following day. These artefacts were all found lying on the surface of undisturbed sandy soil in well cultivated agricultural beds, consistent with the notion that they were fragments from the observed fireball. From now onwards we refer to these stones as the Polonnaruwa stones. Further stones were recovered about one week later on the western banks of the Ratkinda and Mauru Oja reservoirs, approximately $35 \mathrm{~km}$ south-west of Aralagonwila. One witness reported discovering a small cluster of unusual stones $(<5 \mathrm{~g}$ each) lying on the surface of a sandy area adjacent to his garden path approximately $10 \mathrm{~m}$ distance from his home.
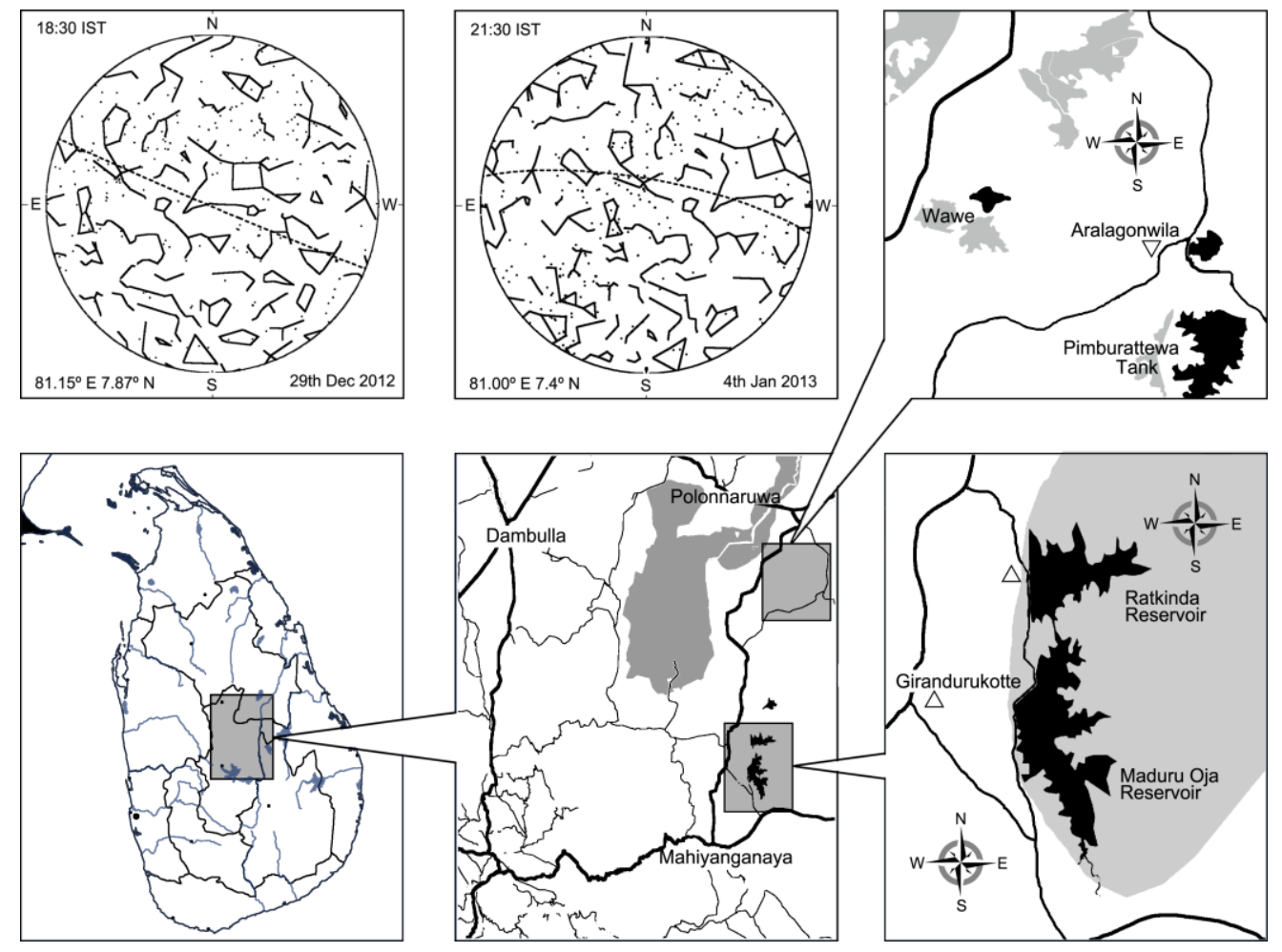

Figure 1. Upper panels show the position of the Taurid radiant in the sky above (left) Aralagonwila $\left(7^{\circ} 46^{\prime} 0^{\prime \prime} \mathrm{N}\right.$ and $\left.81^{\circ} 10^{\prime} 60^{\prime \prime} \mathrm{E}\right)$ at $18: 30 \mathrm{PM}$ on the $29^{\text {th }}$ December 2012 and (centre) Girandanakotte $\left(7^{\circ} 24^{\prime} 14.4^{\prime \prime} \mathrm{N}\right.$ and $\left.81^{\circ} 02^{\prime} 17.9^{\prime \prime} \mathrm{E}\right)$ at $21: 30$ PM on the $4^{\text {th }}$ January 2013. Upper right panel shows a map of the find site of the Polonnaruwa stones $(\nabla)$ near the village of Aralagonwila. Lower right panel shows a map of the find sites of the Ratkinda and Girandanakotte stones $(\triangle)$. 
On the same day an independent witness recovered three stone fragments from the surface of his rice field a few kilometres south-west in the town of Girandanakotte $\left(7^{\circ} 24^{\prime} 14.4^{\prime \prime} \mathrm{N}\right.$ and $\left.81^{\circ} 02^{\prime} 17.9^{\prime \prime} \mathrm{E}\right)$. These three stones were larger, heavier and less porous and were again transported to the Medical Research Institute at the Ministry of Health in Colombo. From here on we refer to these stones as the Ratkinda stones and Girandanakotte stones respectively. The discovery of larger, denser fragments on the SW flight trajectory of the $29^{\text {th }}$ December 2012 event makes pairing between the fragments most likely. We note parenthetically that at the time of the observed fireball event on December 29, 2012 through to the discovery of the Ratkinda and Girandanakotte stones on the $4^{\text {th }}$ January 2013, the Taurid radiant was positioned above the horizon in the Sri Lankan sky (Figure 1).

\section{INITIAL EXAMINATION}

Initial examination of the fragments at the Medical Research Institute in Colombo showed the Polonnaruwa stones to be dark grey or black in colour and poorly compacted (density $<1 \mathrm{~g} \mathrm{~cm}^{-3}$ ). Optical microscopic examination revealed results that were discordant with mainstream theory on meteorites, and in particular the presence of a range of biological morphologies, some exhibiting apparent motility. A sample was then sent to Cardiff University, where studies of freshly cleaved interior surfaces using the Environmental Scanning Electron Microscope at the University's School of Earth and Ocean Sciences were conducted. These studies confirmed the presence of a range of fossilised diatoms and a separate sample was then sent to the United States, where it was investigated by one of us (RBH) using a Hitachi Field Emission Scanning Electron Microscope. Similar examinations by the Department of Geology, University of Peradeniya, Sri Lanka, resulted in swift dismissal of the fragments as possible meteorites. Based on XRD and optical microscope analysis together with the improbability that a meteorite would be recovered from a meteor shower, the fragments were determined to comprise of terrestrial fulgurite, the glassy product of tubes formed when quartzose sand, silica, or soil is heated by lightning strikes.

Our observations however, were inconsistent with this assessment. In particular, representative oxide compositions for $\mathrm{SiO}_{2}$ (73-76 wt\%) were low compared to terrstrial fulgarites that showed values of between $90.2 \mathrm{wt} \%$ (Holland) to 99.0 wt\% (Illinois) (Saikia et al. ${ }^{1}$, 2008) while $\mathrm{K}_{2} \mathrm{O}$ values (9-14 wt\%) were too high compared to typical values for fulgurites of between 0.5-0.75 wt \% . Theses high K-values were particularly difficult to reconcile with the fulgarite hypothesis and were more in keeping with K-Si-rich melts found in a variety of non-terrestrial glasses. In the shock veins of Lchondrites (Goresey et al. ${ }^{2}$, 1997) K-enrichment in shocked isotropic plagioclase results from the fractionation between $\mathrm{K}$ and $\mathrm{Na}$. The $\mathrm{Na}$ is not completely lost from the melt veins but incorporated in liquid phase at high temperate/pressure in majorite-pyrope garnet crystals, (Chen, et al. ${ }^{3}$, 1996a and 1996b). A major part of the K is lost in vapour phase and subsequently scavenged by maskelynite melt pockets close to the melt veins resulting in K-enrichment.

In this study we report on the the physical, chemical and mineral properties of a number of stone samples recovered following the Polonnaruwa event. These results show that the $29^{\text {th }}$ December 2012 fall represents the first well documented example of a meteorite carrying undeniably non-terrestrial biological morphologies providing substantial support for the Hoyle-Wickramasinghe Panspermia hypothesis.

\section{HAND SAMPLES AND CHARACTERISTICS}

For the purpose of this study, two stones from the original samples submitted by the Medical Research Institute in Colombo were selected for analysis. These comprised of a $1.591 \mathrm{~g}$ fragment (designated P159/001) and a $1.661 \mathrm{~g}$ fragment (designated P166/001) both of which had been collected on the evening of the $29^{\text {th }}$ December 2012 in the village of Aralagonwila. Visual examination of the stones confirmed they were poorly compacted with density less than $1 \mathrm{~g} \mathrm{~cm}^{-3}$ i.e. less than all known carbonaceous meteorites. The stones were predominantly black, though dark grey and grey regions could be visually observed along with evidence of a partial fusion crust.

Only a few fragments were recovered from the Ratkinda and Girandanakotte fall sites. In total, three fragments were submitted for analysis from the Ratkinda site comprising of $2.247 \mathrm{~g}, 1.414 \mathrm{~g}$ and $0.966 \mathrm{~g}$ particles. All three fragments bore resemblance to the Polonnaruwa stones and exhibited low composite density with a vitreous outer fusion crust. However, these fragments were entirely black in colour, with no visible signs of either light or dark grey regions. From these samples, the $2.247 \mathrm{~g}$ stone was selected for analysis and was designated as sample M224/001. Two further large stones were selected from three fragments recovered from the Girandanakotte fall site. One much larger, denser stone of 
572.162g plus one smaller stone of 44.127g were selected for further study. Neither of these stones bore particular visual resemblance to the Polonnaruwa stones or the stones recovered from the Ratkinda fall site. These stones were designated as M572/001 and M441/001. In addition to the selected fragments, a sample of sand fulgurite was also analysed for comparative purposes together with a soil sample recovered from the Aralaganwila fall site and a further sample of calcium-rich terrestrial rock selected from the Ratkinda fall site for control purposes. Preliminary oxygen and carbon isotope analysis of the calcium rich control sample produced values of $\delta^{13} \mathrm{C}=-9.716 \pm 0.02$ and $\delta^{18} \mathrm{O}=-6.488 \pm 0.04$ which accord well with the values for soil carbonates determined by T.E. Cerling and J. Quade ${ }^{4}, 1993$.

All selected fragments were initially portioned and prepared at Cardiff University's School of Earth and Ocean Sciences and subsequently studied using a variety of optical and electron microscopic, chemical and mineralogical techniques to both classify and better understand their origins.

\section{EXPERIMENTAL SAMPLES AND ANAYLTICAL METHODS}

A variety of analytical methods were used to examine multiple samples of the Polonnarawa, Ratkinda and Girandanakotte stones (Table 1). $30 \mu \mathrm{m}$ sections were studied using optical, scanning electron microscopy (SEM) and Raman spectroscopy. These included a 30 $\mu$ m polished section of specimen P166/001-01 prepared at the Paleontological Institute, Moscow in Russia using sequential resin boiling and polishing techniques together with a corresponding 30 $\mu \mathrm{m}$ polished section prepared from the same sample at the School of Earth and Ocean Sciences at Cardiff University. Four further polished 30 $\mu \mathrm{m}$ sections, one each of specimens M224/001 and M441/001, together with two of specimen M572/001 were also prepared at Cardiff University. The M572/001 slice comprised of a transverse section cut from specimen M572 of size $\sim 65 \mathrm{~mm}$ x $50 \mathrm{~mm}$ x $3 \mathrm{~mm}$. The two polished $30 \mu \mathrm{m}$ sections were taken from adjacent locations on one face and were selected to incorporate each of four distinct lithologies present on the face of the slab.

Optical microscopy was conducted using an RM-1POL polarising light microscope with $360^{\circ}$ rotating analyser. Image capture was via a 9M pixel digital trinocular camera unit processed by View7 PC software for output to hard drive. Scanning Electron Microscopy (SEM) was conducted using the FEI (Phillips) XL30 FEG ESEM (Environmental Scanning Electron Microscope) FEG (Field Emission Gun) at the School of Earth and Ocean Sciences at Cardiff University. The unit incorporates a secondary electron detector (SE), a back scatter electron detector (BSE) and a gaseous secondary electron detector (GSE). It also has an Oxford Instruments INCA ENERGY (EDX) x-ray analysis system. Image recording is via a SONY video graphics printer or digital by processing image frames in a 16 bit framestore computer for output to hard drive.

Confocal high resolution Raman spectra were acquired using a Renishaw inVia microRaman system at the School of Chemistry, Cardiff University, UK. The unit was fitted with a research grade Leica analytical microscope (4x, 10x, 20x and 40x objectives) and a $514.5 \mathrm{~nm}$ Ar laser line. Data processing was via the Wire2 software application for data output to hard drive. Spectroscopy was performed on both polished and unpolished $30 \mu \mathrm{m}$ thin section samples at room temperature with spectra collected through the 40x objective.

Six further bulk samples were prepared for interior section scanning, two derived from sample P166/001, one each from samples M224/001 and M441/001 and two from sample M572/001. Sample preparation involved the use of a flame sterilised wide-bore hypodermic needle to fracture the fragments before mounting on aluminium stubs.

The FEI (Phillips) XL30 FEG ESEM was also used for electron petrography (BSE Imaging). Elemental abundances were determined using the Analytical Scanning Electron Microscope (A-SEM) at the School of Earth and Ocean Sciences at Cardiff University. The A-SEM comprises of an LEO (Cambridge) S360 Electron Microscope, an Oxford Instruments INCA ENERGY X-Ray analyser and an Oxford Instruments INCA WAVE X-Ray analyser. Calibration was via standards which included $\mathrm{SiO}_{2}$ for $\mathrm{O}-\mathrm{K}, \mathrm{Al}_{2} \mathrm{O}_{3}$ for $\mathrm{Al}-\mathrm{K}, \mathrm{MgO}$ for $\mathrm{Mg}-\mathrm{K}, \mathrm{SiO}_{2}$ for $\mathrm{Si}-\mathrm{K}, \mathrm{GaP}$ for $\mathrm{P}-\mathrm{K}$, Orthoclase for $\mathrm{K}-\mathrm{K}, \mathrm{AgCl}$ for $\mathrm{Cl}-\mathrm{K}$ and Wollastonite for $\mathrm{Ca}-\mathrm{K}$. For the other elements (Na, $\mathrm{P}, \mathrm{Ti}$, and $\mathrm{Mn}$ ) $\mathrm{K}$ factors were estimated using standard calibration curves.

Eleven additional samples, derived from five different bulk sample aliquots (A-E) were analysed using Inductively Coupled Plasma Optical Emission Spectrometry (ICP-OES), Fourier Transform Spectroscopy (FTIR), Triple Oxygen Isotope analysis and X-Ray Diffraction (XRD). 
Table 1 - Experimental Samples

\begin{tabular}{|c|c|c|c|}
\hline Sample & $\begin{array}{l}\text { Mass } \\
(\mathrm{mg})\end{array}$ & Source $^{\text {a }}$ & Description $^{\mathrm{b}}$ \\
\hline \multicolumn{4}{|c|}{ Experimental Samples } \\
\hline P159/001-01 & 448 & AR & $\sim 8 \mathrm{~mm}$ interior fragment for SEM studies at SES-CU \\
\hline P159/001-02 & 177 & AR & $\sim 5 \mathrm{~mm}$ interior fragment for SEM studies at NASA- MSFC \\
\hline P159/001-03 & 512 & AR & Silica-rich powder from aliquot $\mathrm{A}^{\mathrm{c}}$ used for $\mathrm{X}$ ray Diffraction Analysis at SES-CU \\
\hline P159/001-04 & 998 & AR & Silica-rich powder from aliquot $A^{c}$ used for Triple Oxygen Isotope Analysis at UG \\
\hline $\mathrm{P} 159 / 001-05$ & 2048 & AR & Silica-rich powder from aliquot $\mathrm{A}^{\mathrm{c}}$ used for ICP-OES, FTIR and XRF analysis \\
\hline P166/001-01 & - & AR & $\sim 1.2 \mathrm{~cm}$ wide, polished thin section prepared for optical/electron petrography at PI \\
\hline P166/001-02 & - & AR & $\sim 9 \mathrm{~mm}$ wide, polished thin section for optical and electron petrography at SES-CU \\
\hline M224/001-01 & 168 & RK & $\sim 4 \mathrm{~mm}$ interior fragment for SEM studies at SES-CU \\
\hline M224/001-02 & 509 & RK & Silica-rich powder from aliquot $\mathrm{B}^{\mathrm{d}}$ used for X ray Diffraction Analysis at SES-CU \\
\hline M224/001-03 & 1978 & RK & Silica-rich powder from aliquot $\mathrm{B}^{\mathrm{d}}$ used for ICP-OES, FTIR and XRF analysis \\
\hline M224/001-04 & - & RK & $\sim 9 \mathrm{~mm}$ wide, polished thin section for optical and electron petrography at SES-CU \\
\hline M572/001-01 & - & GD & $\sim 1.7 \mathrm{~cm}$ wide, polished thin section for optical and electron petrography at SES-CU \\
\hline M572/001-02 & - & GD & $\sim 1.7 \mathrm{~cm}$ wide, polished thin section for optical and electron petrography at SES-CU \\
\hline M572/001-03 & 1966 & GD & $\sim 10 \mathrm{~mm}$ interior fragment for SEM studies at SES-CU \\
\hline M572/001-04 & 1081 & GD & $\sim 8 \mathrm{~mm}$ interior fragment for SEM studies at SES-CU \\
\hline M572/001-05 & 1667 & GD & Powder from aliquot $\mathrm{C}^{\mathrm{e}}$ used for $\mathrm{X}$ ray Diffraction Analysis at SES-CU \\
\hline M572/001-06 & 1574 & GD & Powder from aliquot $\mathrm{C}^{\mathrm{e}}$ used for ICP-OES, FTIR and CHN analysis \\
\hline M572/001-07 & 1669 & GD & Powder from aliquot $\mathrm{E}^{\mathrm{g}}$ used for $\mathrm{X}$ ray Diffraction Analysis at SES-CU \\
\hline M572/001-08 & 1821 & GD & Powder from aliquot $\mathrm{E}^{\mathrm{g}}$ used for ICP-OES, FTIR and $\mathrm{CHN}$ analysis \\
\hline M441/001-01 & 989 & GD & $\sim 8 \mathrm{~mm}$ interior fragment for SEM studies at SES-CU \\
\hline M441/001-02 & 1027 & GD & Silica-rich powder from aliquot $\mathrm{D}^{\mathrm{f}}$ used for $\mathrm{X}$ ray Diffraction Analysis at SES-CU \\
\hline M441/001-03 & 2048 & GD & Silica-rich powder from aliquot $\mathrm{D}^{\mathrm{f}}$ used for ICP-OES, FTIR and CHN analysis \\
\hline M441/001-04 & - & GD & $\sim 1.7 \mathrm{~cm}$ wide, polished thin section for optical and electron petrography at SES-CU \\
\hline \multicolumn{4}{|c|}{ Control and Comparative Samples } \\
\hline D159/001-01 & 3072 & RK & Soil Carbonate from Dambulla, Sri Lanka \\
\hline F159/001-02 & 1667 & - & Fulgarite from the Sarhara Desert \\
\hline S159/001-05 & 3074 & AR & Soil Sample from Araganwila, Sri Lanka \\
\hline
\end{tabular}

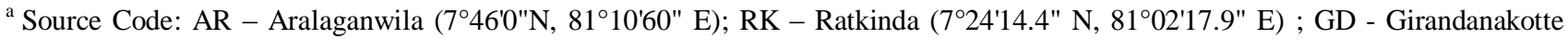
$\left(7^{\circ} 24^{\prime} 14.4^{\prime \prime} \mathrm{N}, 81^{\circ} 02^{\prime} 17.9^{\prime \prime E}\right)$ Samples supplied by Anil Samaranayake and K. Wickramarathne of the Medical Research Institute of the Ministry of Health in Colombo, Sri Lanka.

${ }^{\mathrm{b}}$ Description Code: SES-CU - School of Earth and Ocean Science, Cardiff University; NASA- MSFC NASA Marshall Space Flight Centre; PI - Paleontological Institute, Moscow, Russia; UG - Stable Isotope Laboratory, University of Göttingen, Germany.

${ }^{c}$ Aliquot A - Three interior fragments and dust weighing a combined 2.41g taken from sample P159/001.

${ }^{\mathrm{d}}$ Aliquot B - Dust from interior weighing a combined 1.91g taken from sample M224/001.

${ }^{\mathrm{e}}$ Aliquot C - Two fragments and dust weighing a combined 4.307g taken from a black lithology of sample M572/001.

${ }^{\mathrm{f}}$ Aliquot D - Dust weighing a combined $4.416 \mathrm{~g}$ taken from the interior of sample M441/001.

${ }^{\mathrm{g}}$ Aliquot $\mathrm{E}-$ Seven fragments and dust weighing a combined $4.82 \mathrm{~g}$ taken from a porous region of sample M572/001.

Triple oxygen isotope analyses were conducted in the stable isotope laboratory at the University of Göttingen, Germany. Approximately $2 \mathrm{mg}$ of crushed sample was placed inside a Ni sample holder, evacuated overnight and heated to $70^{\circ} \mathrm{C}$. An infrared (IR) laser $\left(50 \mathrm{~W} \mathrm{CO}_{2}\right.$ laser, $\left.\lambda=10.6 \mu \mathrm{m}\right)$ was used to fluorinate the samples in purified $\mathrm{F}_{2}$ gas under pressures of approximately 20 mbar and sample $\mathrm{O}_{2}$ was purified through the removal of excess $\mathrm{F}_{2}$ by reaction with $\mathrm{NaCl}$ at $110^{\circ} \mathrm{C}$ to form $\mathrm{NaF} . \mathrm{Cl}_{2}$ gas was collected at a cold trap at $-196^{\circ} \mathrm{C}$.

Sample oxygen was then collected at a $5 \AA$ molecular sieve at $-196^{\circ} \mathrm{C}$, expanded into a stainless steel capillary, transported with He carrier gas and re-trapped before release at $92^{\circ} \mathrm{C}$ through a $5 \AA$ molecular sieve GC-column of a Thermo Scientific GasBench II. The GC column was utilised to separate interfering $\mathrm{NF}_{3}$, from $\mathrm{O}_{2}$, as required for analysis of ${ }^{17} \mathrm{O}$ (Pack et al. ${ }^{5}, 2008$ ). The resulting purified sample $\mathrm{O}_{2}$ was then expanded to the dual inlet system of a Thermo MAT 253 gas mass spectrometer. Results are presented in $\delta$ - and $\Delta^{17} \mathrm{O}$-notation. Data are reported relative to SMOW. Error bars are about $\pm 0.1 \%$ for $\delta^{17} \mathrm{O}$ and $\delta^{18} \mathrm{O}$ and about $\pm 0.01 \%$ or better for $\Delta^{17} \mathrm{O}$. The reference gas was 
analysed relative to SMOW calibrated $\mathrm{O}_{2}$ by E. Barkan (Hebrew University of Jerusalem). All $\delta$ values are permil unless otherwise stated.

X-Ray Diffraction was carried out using a Philips PW1710 Automated Powder Diffractometer using $\mathrm{Cu}$ Ka radiation at $35 \mathrm{kV}$ and $40 \mathrm{~mA}$, between 2 and $70^{\circ} 2 \theta$ at a scan speed of $0.04^{\circ} 2 \theta / \mathrm{s}$. From the scans, phases were identified using PCIdentity software and from the peak areas, semi-quantitative analysis was performed and the percentage of each phase calculated. Each of the four samples provided for analysis were powdered, mixed with a small amount of acetone and pipetted out onto glass slides. Detailed phase analysis was performed using Crystal Impact's 'Phase Identification from Powder Diffraction' software module version 2. Sample preparation and analysis was conducted at the School of Earth and Ocean Sciences at Cardiff University.

Whole rock chemical analysis of aliquots of a ground, homogenised powder of the sample fragments were carried out using a Perkin Elmer Dual-View Optima 5300 Inductively Coupled Plasma Optical Emission Spectrometer. Calibration was based on the analysis of reference rock powders USGS DTS-1 (dunite), USGS BCR-2 (basalt) and ANRT BR (basalt). $50 \mathrm{mg}$ aliquots of the samples and standards were dissolved in an Anton Paar Multiwave 3000 microwave digestion unit in high-pressure, high temperature PTFE ('teflon') vessels $\left(210^{\circ} \mathrm{C}, 8 \mathrm{bar}\right)$. The procedure was adapted from Mareels ${ }^{6}$ (2004). Samples were first dissolved in mixtures of concentrated high-purity acids HF, $\mathrm{HNO}_{3}$ and HCL. The bulk composition of the stones has been derived from an average or combination of the results of two separate sample runs. The procedure utilised does not allow the content of Boron to be determined, because the element is added when the mixture is neutralised by the addition of Boric Acid.

InfraRed spectroscopy was conducted using a Perkin-Elmer Spectrum 65 spectrometer equipped with Perkin-Elmer's Universal Attenuated Total Reflectance (ATR) sampling module incorporating a diamond crystal. Samples were prepared by crushing the aliquot contents into a fine powder using a mortar and pestle in order to achieve a good contact with the diamond surface. Verification of apparatus calibration was achieved by performing four background scans and four sample scans. Data output was via Perkin-Elmer's Spectrum 10 software module with spectrum analysis performed using the RRUFF analytical software application incorporating the Caltech Raman database and RRUFF Project database of minerals.

\section{PETROLOGY AND MINEROLOGY}

In thin section, the Polonnaruwa, Ratkinda and Girandanakotte stones exhibit highly porous (Figure 2) poikilitic textures comprising of isotropic silica-rich/plagioclase-like hosts enclosing subangular to subrounded polymineralic grains (Figure 3a,b). Inclusions range in size and shape from mm-sized to smaller (often single) subangular grains that exhibit significant variations in density distribution ( 5\% in sample P166/100-02 to 30\% in M572/100-02). Mineral clasts are often more fractured than the surrounding host (Figure 3d). Common minerals include ilmenite, fayalite, quartz and accessory Fe-Ni metal and zircon.

The chemical composition of the host matrix varies between samples, but all are rich in $\mathrm{SiO}_{2}$. One feature of particular note is that silica-rich melt displays a heterogeneous enrichment in potassium in comparison with crystalline forms. This was most noted in $\mathrm{P} 166 / 001\left(\mathrm{SiO}_{2}=75-80, \mathrm{Al}_{2} \mathrm{O}_{3}=10-15, \mathrm{CaO}=0.1-1.5, \mathrm{Na}_{2} \mathrm{O}=0-1, \mathrm{~K}_{2} \mathrm{O}=9-11, \mathrm{FeO}=0-5.5, \mathrm{TiO}_{2}=\right.$ $0-1.0)$ and sample $\mathrm{M} 224 / 001\left(\mathrm{SiO}_{2}=70-75, \mathrm{Al}_{2} \mathrm{O}_{3}=12-15, \mathrm{CaO}=0.5-0.3, \mathrm{Na}_{2} \mathrm{O}=0-0.2, \mathrm{~K}_{2} \mathrm{O}=9-11, \mathrm{FeO}=0-0.2\right.$, $\mathrm{TiO}_{2}=0-0.1$ ), all values in wt $\%$. K-rich glasses of similar composition have been reported in a variety of non-terrestrial material ranging from rare iron meteroites (e.g. Mittlefehldt et al. ${ }^{7}, 1998$; Ruzicka et al. ${ }^{8}, 2006$ ) to LL chondritic breccias (Bischoff et al. ${ }^{9}, 1993$; King et al. ${ }^{10}, 2005$; Sokol et al. ${ }^{11}$, 2007) and Lunar granites collected during the Apollo missions (Papike et al. $\left.{ }^{12}, 1998\right)$. The Lunar granites in particular were characterised by high $\mathrm{SiO}_{2}(60$ to $74 \mathrm{wt} \%)$ and $\mathrm{K}_{2} \mathrm{O}(2$ to $10.4 \mathrm{wt} \%)$, and low $\mathrm{Na}_{2} \mathrm{O}\left(0.4\right.$ to $1.9 \mathrm{wt} \%$ ) (Papike et al. $\left.{ }^{12}, 1998\right)$.

Similar compositional values were reported by Leroux and Cordier ${ }^{13}(2006)$ in silica-rich pockets occurring as patches between maskelynite laths or between pyroxene and maskelynite in the Martian meteorite NWA 856. The bulk chemical composition of the pockets differed from one another $\left(\mathrm{SiO}_{2}=75-80, \mathrm{Al}_{2} \mathrm{O}_{3}=11-15, \mathrm{CaO}=0.5-1.5, \mathrm{Na}_{2} \mathrm{O}=2-5, \mathrm{~K}_{2} \mathrm{O}=\right.$ $1-5, \mathrm{FeO}=0.2-1, \mathrm{TiO}_{2}=0.2-0.8$ ) but along with Lunar granites accord reasonably well with equivalent compositional values observed in P166/001 and M224/001. 

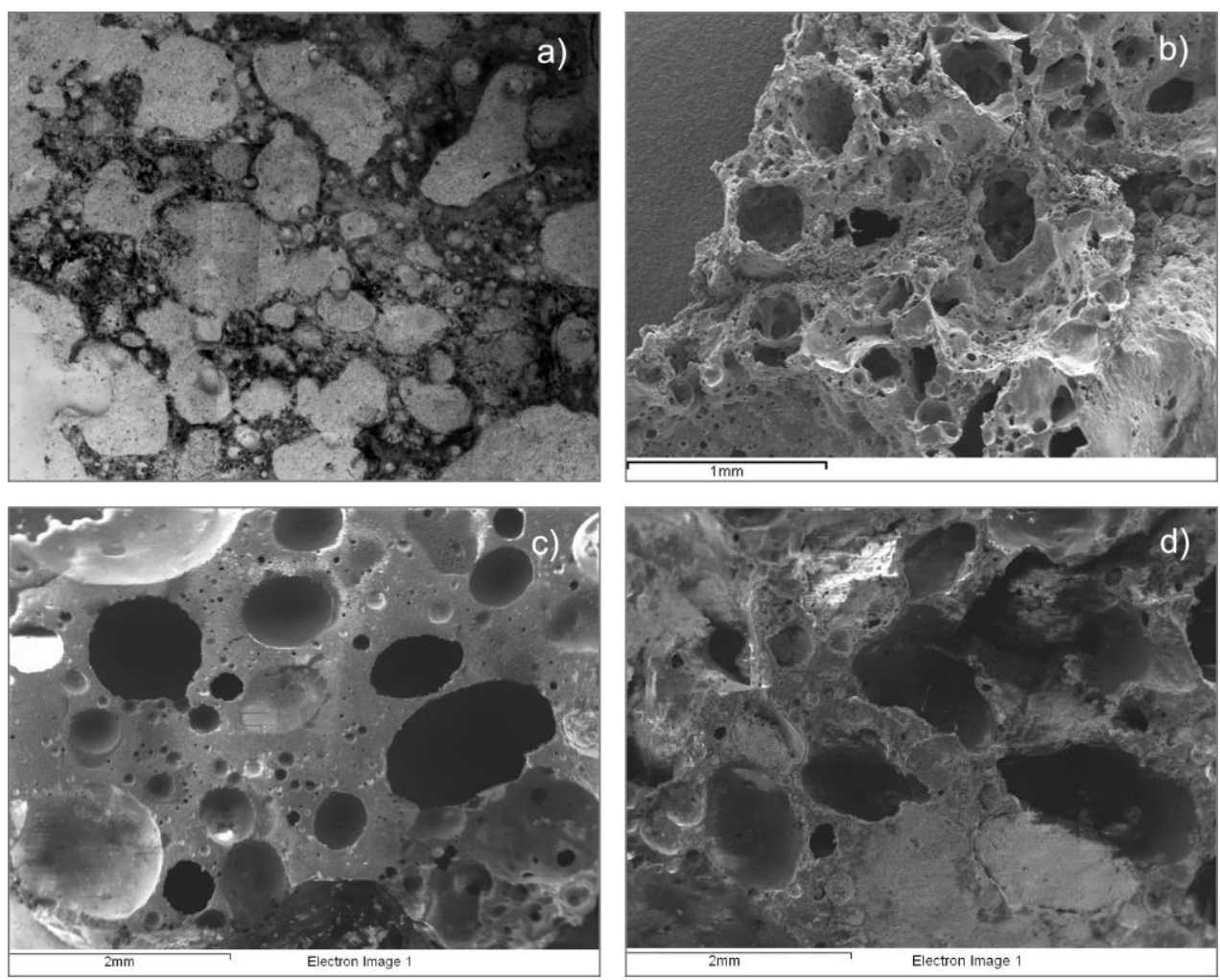

Figure 2 shows the highly porous nature of P166/100 and M224/100. (a) Thin section montage of P166/100 in plane polarised light. Voids show up in light grey (resin pores) with K-rich glass in dark grey/black. (b) SEM (GSE) of P166/001 showing extensive voids. (c) SEM (BSE) of M224/001 (polished) and (d) SEM (GSE) of M224/001 using the FEI (Phillips) XL30 FEG at the School of Earth and Ocean Sciences at Cardiff University.

K-enrichment was also observed in the matrix melt of M441/001 and M572/001. Here, the composition of the host matrix was more plagioclase-like $\left(\mathrm{SiO}_{2}=50-60, \mathrm{Al}_{2} \mathrm{O}_{3}=19-27, \mathrm{CaO}=2-7, \mathrm{Na}_{2} \mathrm{O}=2-7, \mathrm{~K}_{2} \mathrm{O}=1.4-3.8, \mathrm{FeO}=1-11\right.$, $\mathrm{TiO}_{2}=0-1.5$; all values in wt \%). Within the matrix, silica-rich melt pockets exhibited well-defined interfaces with the adjacent phase and a general absence of cleavage, intergranular cracks or shock induced fractures (Figure 3c). Table 2 displays representative SEM-EDAX compositions (wt\%) for the plagioclase-like glass host of M441/001 and M572/001, together with comparative compositions (wt\%) for maskelynite in NWA 856 (Leroux and Cordier ${ }^{13}, 2006$ ), Dar al Gani 476 and Dar al Gani 355 (Chen ${ }^{14}$, 1999).

It is noted that in the shock veins of L-chondrites (Goresey et al. ${ }^{15}$, 1997) K-enrichment in shocked isotropic plagioclase results from the fractionation between $\mathrm{K}$ and $\mathrm{Na}$. The $\mathrm{Na}$ is not completely lost from the melt veins but incorporated in liquid phase at high temperate/pressure in majorite-pyrope garnet crystals (Chen, et al. ${ }^{16,17}$, 1996a and 1996b). A major part of the $\mathrm{K}$ is lost in vapour phase and subsequently scavenged by maskelynite melt pockets close to the melt veins resulting in K-enrichment. In the Peace River L-chondrite, elemental X-ray maps of shock veins show the presence of Krich phases in the shock induced fractures of pyroxene and olivine crystals that are in contact with both the veins and the maskelynite. Table 2 displays representative SEM-EDAX compositions (wt\%) for the Si-K-rich glass host matrix of P166/001 together with comparative compositions (wt\%) for NEA003-A (Haloda et al. ${ }^{18}, 2009$ ), NWA 856 (Leroux and Cordier $^{13}, 2006$ ) and Miles IIE (Ruzicka and Hutson $\left.{ }^{19}, 2010\right)$.

Quartz was detected in P166/100, M441/001 and M572/001 but was not found in sample M224/001. In P166/100 it is characterised by a number of euhedral and subhedral grains $(1-10 \mu \mathrm{m}$, commonly $<1 \mu \mathrm{m})$ with elongate to equant shapes. 

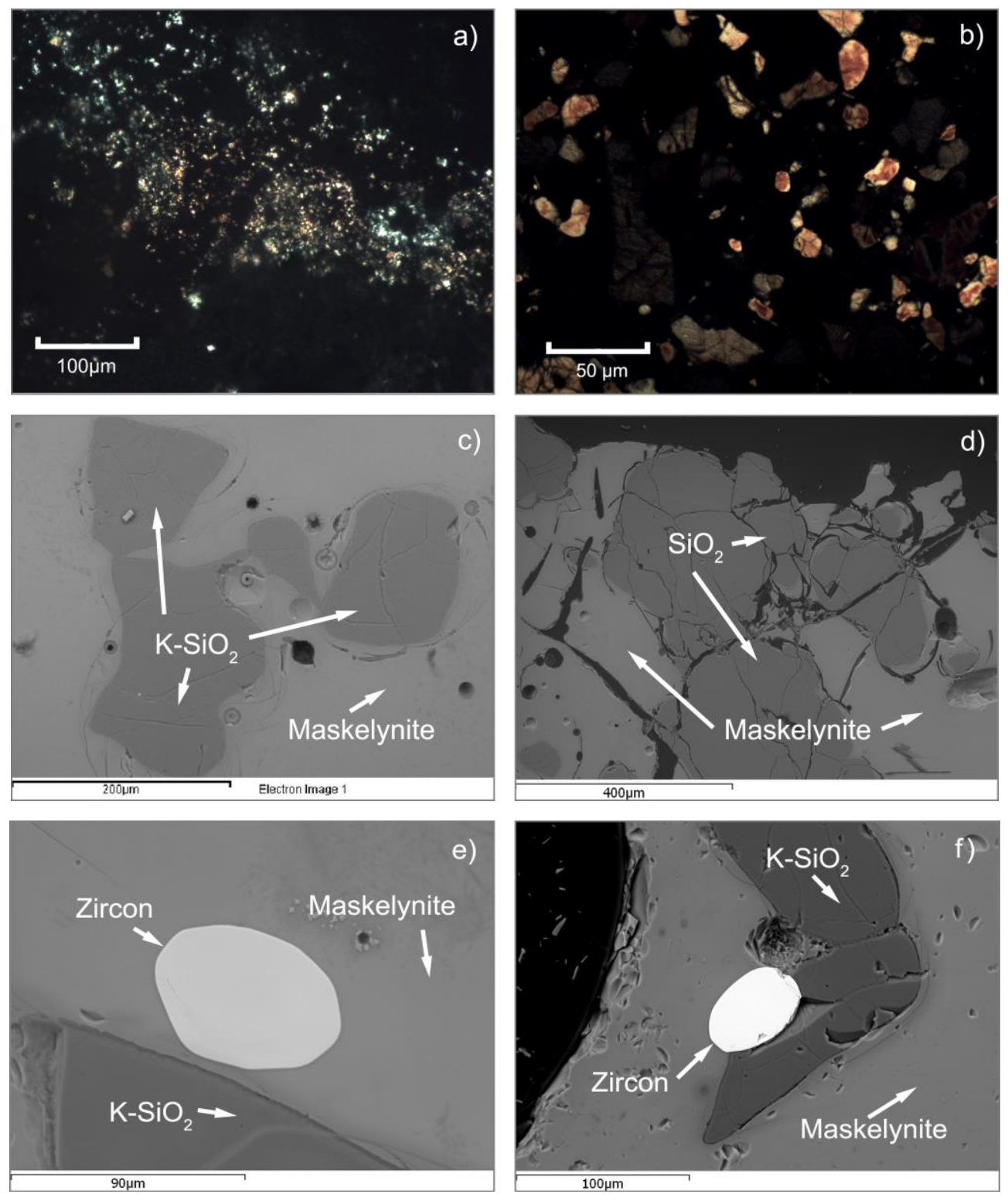

Figure 3 shows mineral inclusions in P166/100 and M572/001. (a) Thin section montage of P166/100 in plane polarised light (crossed nicols), (b) optical micrograph of M572/100 in plane polarised light (crossed nicols), (c) and (d) SEM backscatter micrograph s of M572/100 - note the smooth, featureless texture of the maskelynite (light grey) and fine fractures in the silica glass (dark grey), (e) and (f) subrounded/well-rounded zircon grains close to $\mathrm{SiO}_{2}$-rich melt pockets - note interfaces with adjacent phases were welldefined and in (f) project into the $\mathrm{SiO}_{2}$-rich glass suggesting zircon inclusions were adrift in the surrounding melt.

Larger grains were present in M441/001 and M572/001 where mosaic extinction was a prominent feature indicating deformation of crystal structure, with numerous cracks and fractures suggesting shock process. Planar deformation features (amorphous lamellae) were not evident in the samples analysed. Several polymorphs of $\alpha$-quartz were also present in P166/001, M441/001 and M572/001 including the high temperature/pressure quartz polymorphs, cristobalite and stishovite.

The presence of quartz in meteorites has been reported in silica rich pockets of order $\sim 100 \mu \mathrm{m}$ in the Martian meteorite NWA 856 (Leroux and Cordier ${ }^{13}$, 2006). Quartz grains of size $\sim 5 \mu \mathrm{m}$ together with similar sized grains of the high temperature polymorph cristobalite were evident in polarised light observations under an optical microscope. 
Table 2

Representative compositions of Si-K-rich glass and shocked isotropic plagioclase (Maskelynite)

\begin{tabular}{|c|c|c|c|c|c|c|c|c|c|c|c|c|}
\hline & & \multicolumn{2}{|c|}{$\begin{array}{r}\text { P166/001: } \\
\text { Si-K-rich glass }\end{array}$} & \multicolumn{3}{|c|}{$\begin{array}{l}\text { NEA003-A, NWA 856, } \\
\text { Miles: Si-K-rich glass }\end{array}$} & \multicolumn{3}{|c|}{$\begin{array}{r}\text { M441/001, M572/001: } \\
\text { Maskelynite }\end{array}$} & \multicolumn{3}{|c|}{$\begin{array}{l}\text { NWA 856, DAG 355, } \\
\text { DAG 476: Maskelynite }\end{array}$} \\
\hline & $\mathrm{S} 1$ & $\mathrm{~S} 2$ & S3 & $\mathrm{S} 4$ & S5 & S6 & S7 & S8 & S9 & S10 & S11 & S12 \\
\hline $\mathrm{SiO}_{2}$ & 76.56 & 74.70 & 73.16 & 63.9 & 75.8 & 76.10 & 59.01 & 54.09 & 52.65 & 52.16 & 66.55 & 55.2 \\
\hline $\mathrm{Al}_{2} \mathrm{O}_{3}$ & 10.37 & 15.00 & 12.75 & 18.1 & 14.3 & 12.80 & 23.91 & 26.12 & 19.57 & 29.45 & 22.35 & 29.8 \\
\hline $\mathrm{Na}_{2} \mathrm{O}$ & 0.72 & 0.17 & nd & 1.12 & 2.2 & 0.67 & 6.65 & 2.49 & 2.34 & 3.98 & 8.14 & 2.0 \\
\hline $\mathrm{MgO}$ & 0.26 & 0.24 & 0.05 & 0.02 & nd & 0.32 & 0.00 & 0.49 & 0.97 & 0.17 & 0.08 & nd \\
\hline $\mathrm{K}_{2} \mathrm{O}$ & 9.11 & 9.00 & 9.27 & 14.8 & 5.5 & 8.67 & 1.40 & 3.59 & 3.76 & 0.08 & 1.64 & 0.4 \\
\hline $\mathrm{CaO}$ & 1.01 & 0.28 & 0.06 & 0.02 & 0.5 & 0.45 & 6.73 & 1.94 & 2.53 & 13.42 & 1.69 & 12.2 \\
\hline $\mathrm{FeO}$ & 4.43 & 0.00 & 0.00 & 0.96 & 1.1 & 0.62 & 1.10 & 8.67 & 11.02 & 0.60 & 0.42 & 0.5 \\
\hline $\mathrm{TiO}_{2}$ & 0.77 & 0.00 & 0.00 & 0.08 & 0.8 & 0.56 & 0.00 & 0.88 & 1.36 & nd & nd & nd \\
\hline $\mathrm{MnO}$ & nd & 0.00 & 0.00 & $<0.01$ & nd & 0.04 & 0.00 & 0.48 & 0.47 & nd & nd & nd \\
\hline Total & 103.22 & 99.40 & 95.29 & 99.01 & 100.2 & 100.23 & 98.80 & 98.75 & 94.67 & 99.87 & 100.87 & 94.11 \\
\hline \multicolumn{13}{|c|}{ Number of cations (oxygens) $=8$} \\
\hline $\mathrm{Si}$ & 3.268 & 3.271 & 3.343 & - & 3.57 & - & 2.681 & 2.527 & 2.622 & 2.38 & 2.90 & 2.94 \\
\hline $\mathrm{Al}$ & 0.575 & 0.780 & 0.692 & - & 0.40 & - & 1.290 & 1.450 & 1.158 & 1.58 & 1.14 & 0.93 \\
\hline $\mathrm{Na}$ & 0.065 & 0.015 & - & - & 0.10 & - & 0.586 & 0.226 & 0.226 & 0.35 & 0.69 & 0.10 \\
\hline $\mathrm{Mg}$ & 0.018 & 0.016 & 0.003 & - & - & - & - & 0.034 & 0.072 & 0.01 & 0.00 & \\
\hline $\mathrm{K}$ & 0.545 & 0.502 & 0.541 & - & 0.17 & - & 0.081 & 0.214 & 0.239 & 0.00 & 0.09 & 0.01 \\
\hline $\mathrm{Ca}$ & 0.051 & 0.013 & 0.003 & - & 0.03 & - & 0.328 & 0.097 & 0.135 & 0.66 & 0.08 & 0.70 \\
\hline $\mathrm{Fe}$ & 0.173 & - & - & - & 0.05 & - & 0.042 & 0.339 & 0.459 & 0.04 & 0.01 & 0.02 \\
\hline $\mathrm{Ti}$ & 0.027 & - & - & - & 0.02 & - & - & 0.031 & 0.051 & - & - & \\
\hline $\mathrm{Mn}$ & - & - & - & - & - & - & - & 0.019 & 0.020 & - & - & \\
\hline Tota & 4.722 & 4.597 & 4.582 & - & 4.34 & - & 5.007 & 4.937 & 4.981 & 5.02 & 4.91 & 5.092 \\
\hline
\end{tabular}

Nd - not detected. S1 - P166/001; S2, S3 - M224/001; S4 - Miles IIE, Ruzicka and Hutson ${ }^{19}$, 2010; S5 - Northwest Africa 856, Leroux and Cordier $^{13}$, 2006; S6 - Northeast Africa 003-A, Haloda et al. ${ }^{18}$, 2009; S7 - M572/001; S8, S9 - M441/001; S10 - Dar al Gani 476, Chen, M. ${ }^{16}$, 1999; S11 - Dar al Gani 355, Chen, M. ${ }^{17}$, 1999; S12 - Northwest Africa 856, Leroux and Cordier ${ }^{13}, 2006$.

In some pockets the minerals occurred as thin elongate grains radiating from a common point. Such observations accord well with comparative observations of sample P166/001 though instances of larger sized silica-rich grains $(<50 \mu \mathrm{m})$ in all samples were also detected. In most instances a homogeneous mixture of quartz and cristobalite was observed. Even at relatively small sample areas, Raman spectra displayed consistent evidence of contributions from both quartz and cristobalite. At this stage, it remains uncertain if these silica-rich inclusions represent evidence of formation by hydrothermal alternation or alternatively, direct evidence for silica enrichment by igneous processes, though the presence of larger sized silica grains in samples M441/001 and M572/001 tentatively suggest the latter.

Inclusions of zircon were present in samples of M224, M572 and M441 but were not detected in P166/100. These were characterised by rare, subrounded to well-rounded grains $(\sim 100 \mu \mathrm{m})$, commonly located close to numerous $\mathrm{SiO}_{2}$-rich melt pockets (Figure 3e). Interfaces with adjacent phases were well-defined and occasionally projected into the $\mathrm{SiO}_{2}$-rich glass (Figure 3f) suggesting zircon inclusions were adrift in the surrounding melt. SEM-EDAX representative compositions $\left(\mathrm{SiO}_{2}=31.41-32.54, \mathrm{ZrO}_{2}=52.73-56.70, \mathrm{~W}=2.17-2.50, \mathrm{wt} \%\right)$ and ion ratios $(\mathrm{Zr} / \mathrm{Si}=0.89 \& \mathrm{Si} / \mathrm{O}=$ 0.25) are consistent with that of Zircon (empirical formula $\mathrm{Zr}_{0.9} \mathrm{Hf}_{0.05} \mathrm{REE}_{0.05} \mathrm{SiO}_{4}$ ). Whilst REE's were not detected it was noted that these may have been present in quantities below the detection limit of the spectrometer which may similarly account for the observed absence of hafnium (Hf). Spot SEM-EDAX spectra indicate some enrichment in $\mathrm{ZrO}_{2}$ at interfaces with adjacent phases. This may be the result of inclusions of baddeleyite grains in the melt that have been observed at the margin of polycrystalline zircon in the lunar meteorite Dhofar 458 (Zhang et al. ${ }^{20}, 2011$ ). If this is confirmed, it would suggest very high shock pressures and temperatures (> 60 GPa and $>\sim 1700^{\circ} \mathrm{C}$, respectively), during which the U-Pb system of recrystallization would have been extensively or totally reset. 
In all samples analysed olivine was characterised by common subhedral to anhedral grains exhibiting fayalitic compositions $(\mathrm{FeO}=69.2-77.93$, wt $\%)$. They were found adjacent to, or enclosed within, $\mathrm{K}_{-} \mathrm{SiO}_{2}$-rich phases in P166/001 but more commonly enclosed within isotropic plagioclase in M441 and M572. Compositions of olivine were generally impure with minor $\mathrm{Al}_{2} \mathrm{O}_{3}(2-3 \mathrm{wt} \%), \mathrm{TiO}_{2}(0.5-2 \mathrm{wt} \%)$ and $\mathrm{V}_{2} \mathrm{O}_{5}(0-0.8 \mathrm{wt} \%)$. Ilmenite was common in all samples, occurring as sub-rounded to elongate grains $(<300 \mu \mathrm{m})$ with some impurities $\mathrm{Al}_{2} \mathrm{O}_{3}(2-4 \mathrm{wt} \%), \mathrm{SiO}_{2}(1-4 \mathrm{wt} \%)$.

\section{SHOCK FEATURES}

In the previous sections we determined that the Polonnaruwa, Ratkinda and Girandanakotte stones can be characterized by a combination of K-rich glasses and plagioclase feldspar, olivine and accessory iron oxides and iron-titanium oxides. This clearly indicates an extrusive igneous origin with a formation process resulting from the rapid cooling of lava exposed at or very near the surface of a planet or moon. Consequently, the presence of high pressure minerals indicating shock metamorphism would be particularly inconsistent with a terrestrial origin. By contrast, the presence of high pressure minerals indicating dislocation from the parent body would be a clear indicator of a meteoritic origin. The presence of such minerals is frequently used to provide clues about the impact processes that excavated, launched and delivered these samples to Earth. For example, the 2011 meteorite fall, Tissint, was found to contain a number of highpressure phases including seven minerals and two mineral glasses indicating a shock and temperature gradient of $\sim 25 \mathrm{GPa}$ and $\sim 2,000^{\circ} \mathrm{C}$.

\subsection{Maskelynite}

Maskelynite is a clear, glassy pseudomorph of plagioclase first described in the Shergotty basaltic achondrite by Tschermak in 1872. It forms by the quenching of dense mineral melts produced by high-pressure shock waves typically of order $\sim 25 \mathrm{GPa}$. The far-infrared spectral characteristics of maskelynite provide useful information about the nature of a given sample and its relative position between crystalline and amorphous state. For example, the absorption spectra in the region $580 \mathrm{~cm}^{-1}$ to $380 \mathrm{~cm}^{-1}$ that is dominated by the Si-O-Si or Si-O-Al absorption band (Cohen and Roy ${ }^{21}$, 1965) and controlled by the ordering between $\mathrm{Si}$ and $\mathrm{O}$ or $\mathrm{Al}$ and $\mathrm{O}$ causes an observable shift in the peak present at $380 \mathrm{~cm}^{-1}$ in crystalline plagioclase towards $480 \mathrm{~cm}^{-1}$ in fully fused maskelynite (Bunch and Cohen ${ }^{22}, 1967$ ).

Figures 4 and 5 show the FTIR spectral characteristics of five samples of the Polonnaruwa, Ratkinda and Girandanakotte stones that were analysed with reference to the $380 \mathrm{~cm}^{-1}$ to $1250 \mathrm{~cm}^{-1}$ region. The FTIR spectra reveal a number of absorption bands in the 380-480 $\mathrm{cm}^{-1}$ region, with clear movement of the $380 \mathrm{~cm}^{-1}$ feature to $416 \mathrm{~cm}^{-1}$ in sample P159/001-05 and a corresponding shift of the feature to $443 \mathrm{~cm}^{-1}$ in sample M224/001-03. The greatest shift of this feature was observed in M572/001-08 at a wavelength of $451 \mathrm{~cm}^{-1}$ clearly demonstrating the stones exhibit a range of transitional states between crystalline and amorphous phase. Further examination indicates a close similarity between the Si-O-Si or Si-O-Al absorption regimes in samples M572/001-08 and M441/001-03 with features at $459 \mathrm{~cm}^{-1}, 451 \mathrm{~cm}^{-1}$, $443 \mathrm{~cm}^{-1}, 436 \mathrm{~cm}^{-1}, 431 \mathrm{~cm}^{-1}$ and $411 \mathrm{~cm}^{-1}$ in M441/001-03 corresponding to features at $458 \mathrm{~cm}^{-1}, 451 \mathrm{~cm}^{-1}, 444 \mathrm{~cm}^{-1}$, $431 \mathrm{~cm}^{-1}$ and $410 \mathrm{~cm}^{-1}$ in M572/001-08. Indeed the general correspondence of absorption features in the broad $380 \mathrm{~cm}^{-1}$ to $1250 \mathrm{~cm}^{-1}$ region between all samples suggest probable commonality of composition.

A number of additional absorption bands were detected in the $500-800 \mathrm{~cm}^{-1}$ and $800-1175 \mathrm{~cm}^{-1}$ region. The $800-1175$ $\mathrm{cm}^{-1}$ bands are due to the Si-O stretching vibration, and absorption features present in all samples in this region are consistent with the $800 \mathrm{~cm}^{-1}, 958 \mathrm{~cm}^{-1}$ and $1088 \mathrm{~cm}^{-1}$ bands due to the presence of amorphous silica (Ojama ${ }^{23}, 2003$ ).

The Si-O-Si bending vibration region of quartz $\left(400-700 \mathrm{~cm}^{-1}\right)$ includes a band at $695 \mathrm{~cm}^{-1}$ that is unique to the crystalline phase (Parthasarathy et al. ${ }^{24}$, 2001). In all samples analysed except M224/001-03 the $695 \mathrm{~cm}^{-1}$ band was detected indicating the presence of crystalline quartz. The absence of the $695 \mathrm{~cm}^{-1}$ feature in M224/001-03 suggests that in this sample the silica mineral was entirely in amorphous form. The absorption band at $695 \mathrm{~cm}^{-1}$ is due to vibrations in the octahedral site symmetry while a corresponding band at $780 \mathrm{~cm}^{-1}$ is due to vibrations in the tetrahedral site symmetry (Schneider ${ }^{25}$, 1974; Parthasarathy et al. ${ }^{24}, 2001$, Saika et al. ${ }^{26}, 2007$ ). The octahedral site symmetry is weaker than the tetrahedral site symmetry resulting in structural damage being observed in the $695 \mathrm{~cm}^{-1}$ region first. A band corresponding to the $780 \mathrm{~cm}^{-1}$ feature was present in M441/001-03 (778 $\left.\mathrm{cm}^{-1}\right)$, M572/001-08 $\left(779 \mathrm{~cm}^{-1}\right)$, M572/001-06 $\left(778 \mathrm{~cm}^{-1}\right)$ and P159/001-05 $\left(776 \mathrm{~cm}^{-1}\right)$ but was not present in M224/001-03 indicating that in this sample shock/thermal deformation was more severe. 

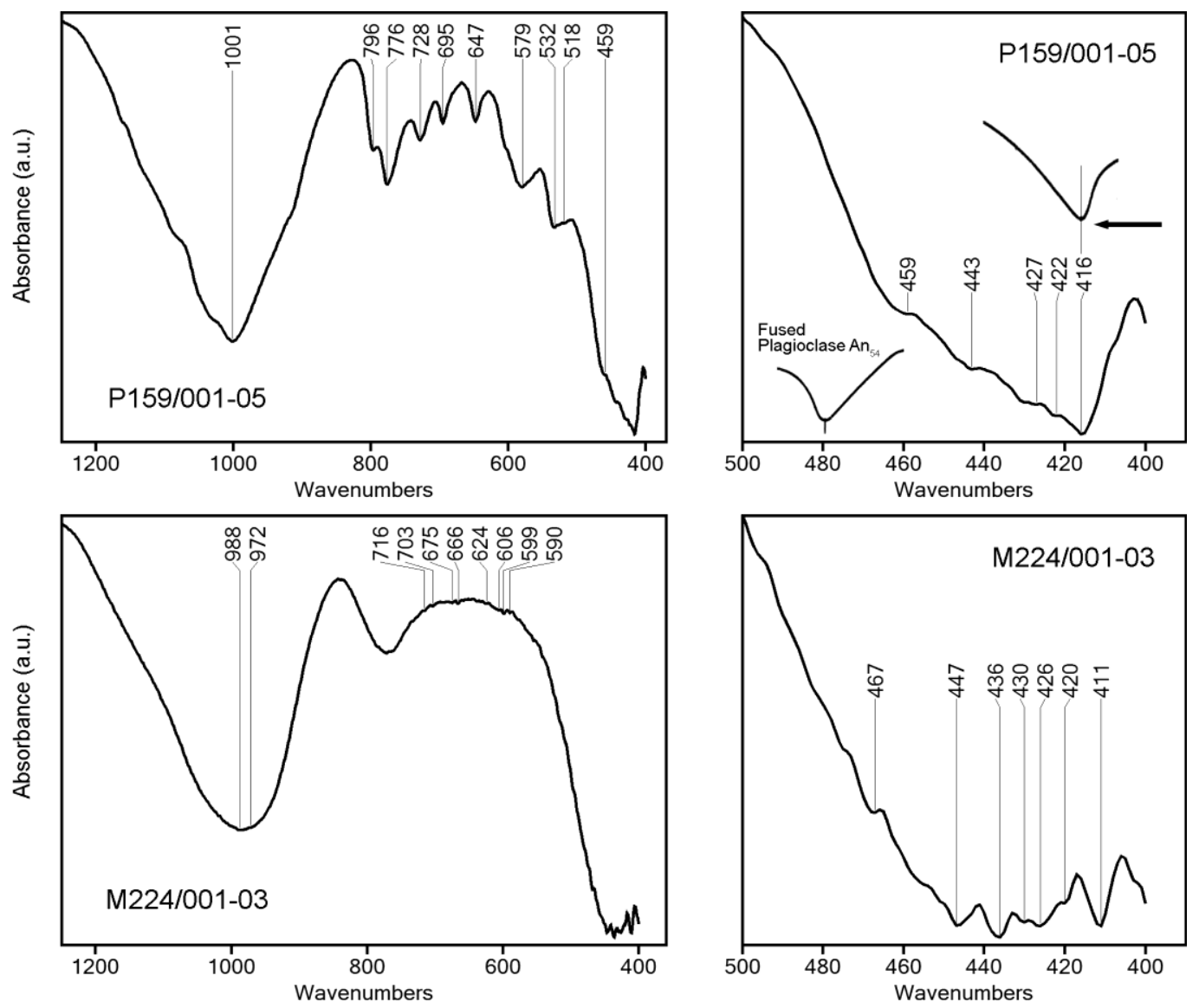

Figure 4: Shows FTIR spectra for samples P159/001-05 and M224/001-03. The degradation of spectral features in the $480 \mathrm{~cm}^{-1}$ to $580 \mathrm{~cm}^{-1}$ region can be seen in M224/001-03. The band at $459 \mathrm{~cm}^{-1}$ corresponds to the Si-O asymmetrical band of vibration. Note the absence of a band at $780 \mathrm{~cm}^{-1}$ due to vibrations in tetrahedral site symmetry (Schneider ${ }^{25}, 1974$; Parthasarathy et al. ${ }^{24}$, 2001, Saika et al. $\left.{ }^{26}, 2007\right)$.

\subsection{High Pressure Minerals}

Substantial evidence of intense shock deformation was commonly observed in crystals of olivine, quartz and accessory ilmenite. In the case of olivine this was characterized by physical deformation features, with some crystals displaying Raman spectra with broadened bands indicating intense lattice distortion. Figure 7 shows the Raman spectra of sample olivine crystals. In some areas, these heavily distorted crystals show an additional Raman band near $750 \mathrm{~cm}^{-1}$ suggesting the local formation of $\mathrm{Si}$-O-Si bridges as in $(\mathrm{Mg}, \mathrm{Fe})_{2} \mathrm{SiO}_{4}$-wadsleyite, the high-pressure polymorph of olivine (Gillet et al. $\left.^{27}, 2002\right)$.

The presence of wadsleyite was further confirmed by XRD analysis of sample M572/001-05. Here, five different samples of the Polonnaruwa, Ratkinda and Girandanakotte stones were analysed for bulk major and trace crystalline compositions using X-ray diffraction at the School of Earth and Ocean Sciences, University of Cardiff. These included three interior fragments and dust weighing a combined 2.41g from sample P159/001, 1.91g of interior dust from sample M224/001 and dust weighing a combined 4.416g taken from sample M441/001. A further two aliquots were prepared from sample M572/001 comprising of two fragments and dust taken from a dark region (designated M572/001-05) and seven fragments and dust weighing a combined 4.82g taken from a porous region (designated M572/001-07). Two further samples comprising of a sample of sand and a carbonate stone taken from Araganwila and Dambulla respectively were also analysed. 

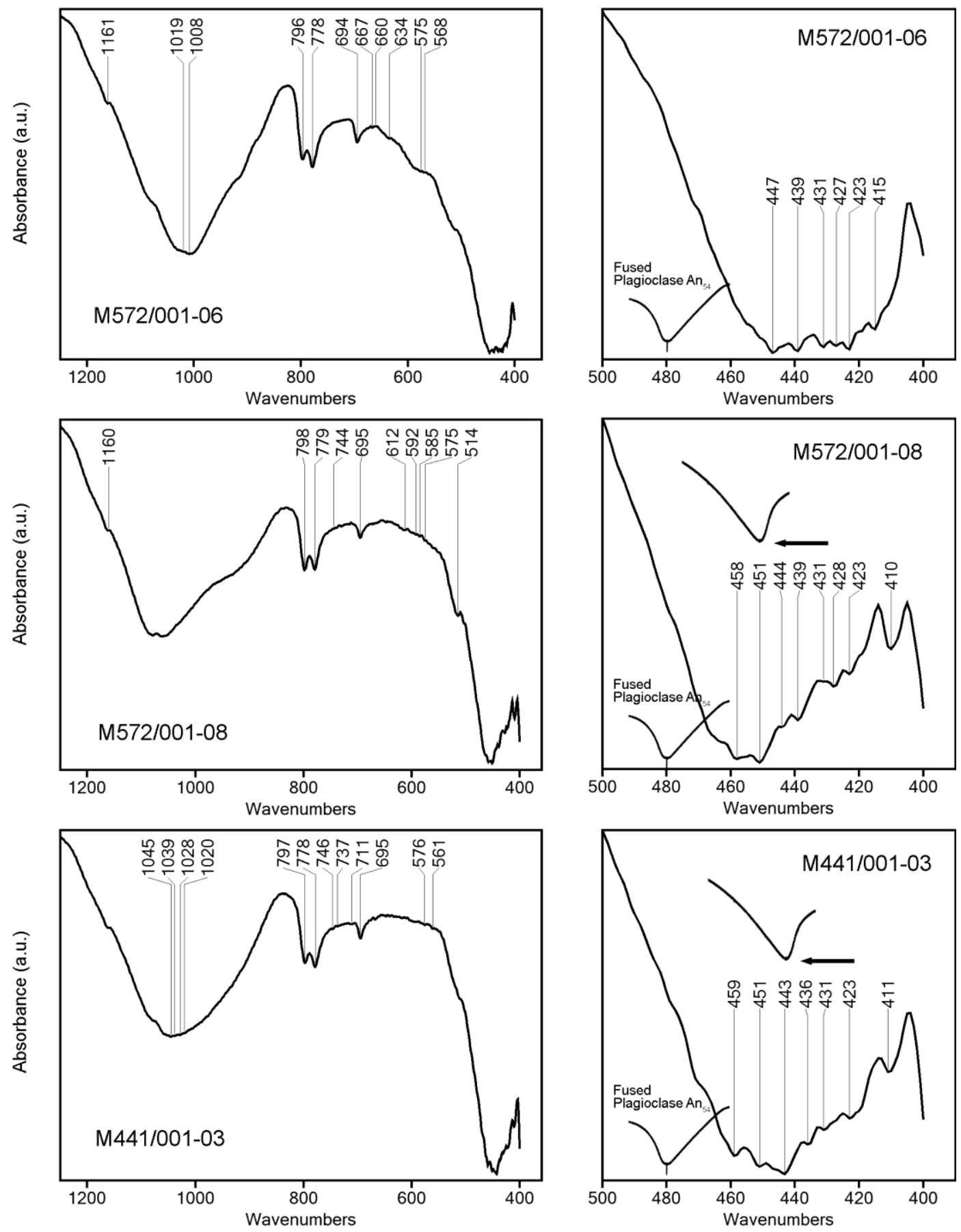

Figure 5: Show FTIR absorption spectra for samples M572/001-06, M572/001-08 and M441/001-03. Note the movement of the 380 $\mathrm{cm}^{-1}$ absorption feature in crystalline plagioclase (Bunch and Cohen, 1967) towards the $480 \mathrm{~cm}^{-1}$ region in fused plagioclase demonstrating a range of transitional states between crystalline to amorphous state between the samples. Note also bands at $778 \mathrm{~cm}^{-1}$ and $795 \mathrm{~cm}^{-1}$ corresponding to matching bands in the IR spectra of Shergotty maskelynite (Bunch and Cohen ${ }^{22}, 1967$ )

X-Ray Diffraction patterns for the selected samples P159/001-03, M224/001-02, M572/001-02, M572/001-05, M572/001 (bulk), M441/001-02, S159/001-05 and D159/001-01 (control) are represented in Figures 8 and 9. A number of peaks were identified in M572/001-05. In particular these were noted at $33.25^{\circ} 2 \theta$ and $62.67^{\circ}$ with further unassigned peak contributions at $39.62^{\circ} 2 \theta, 61.90^{\circ} 2 \theta, 62.27^{\circ} 2 \theta$ and $67.99^{\circ} 2 \theta$. These unassigned features correspond to reported 

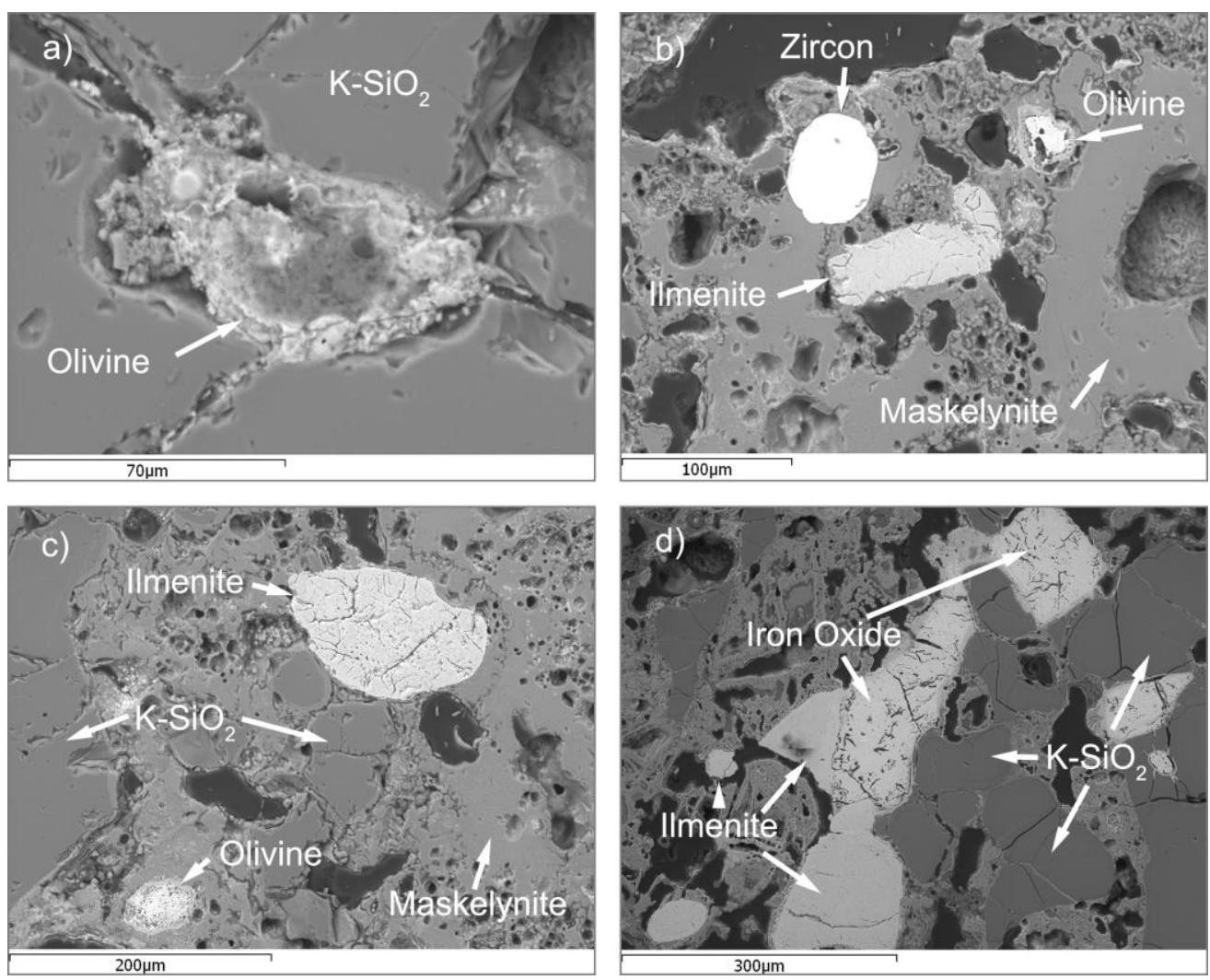

Figure 6 shows SEM backscatter micrographs of a) a deformed olivine crystal embedded in $\mathrm{K}$-rich $\mathrm{SiO}_{2}$ glass in sample P166/001, b) Zircon in M441/001exhibiting enrichment in $\mathrm{ZrO}_{2}$ at the interface with adjacent maskelynite - interpreted as the likely inclusion of baddeleyite grains as observed at the margin of polycrystalline zircon in the lunar meteorite Dhofar 458 (Zhang et al. $\left.{ }^{20}, 2011\right)$, c) and d) typical polymineralic inclusions in M572/001. Note here the presence of ilmenite grains adjacent to high FeO composites indicating the high pressure disproportionment of ilmenite into mixed oxides. All images were taken using the FEI (Phillips) XL30 FEG at the School of Earth and Ocean Sciences at Cardiff University.

mineral data for wadsleyite (Holl C. M. et al. ${ }^{28}$, 2008). The presence of wadsleyite would suggest a minimum enduring shock pressure of $\sim 20 \mathrm{GPa}$. Results for M572/001-07 identified similar crystalline phases to that of M572/001-05 including quartz, cristobalite, olivine (fayalite), hercynite, anorthite and wadsleyite. One further phase was present with strong features exhibited at $35.98^{\circ} 2 \theta, 42.29^{\circ} 2 \theta$ and $61.21^{\circ} 2 \theta$ that was identified from the literature as wuestite (Wyckoff R. W. G. ${ }^{29}, 1963$ ).

Further example of shock was observed in the formation of the high temperature $\mathrm{SiO}_{2}$ polymorph cristobalite within quartz crystals. Figure 7 shows the Raman spectra of one such example found in sample M441/001. Here the spectrum was acquired through a $40 \mathrm{x}$ objective with a beam size occupying approximately $25 \%$ of the crystal's surface area. Library spectra for quartz and cristobalite are also shown for comparison, but primary and secondary spectral features in the $100 \mathrm{~cm}^{-1}$ to $500 \mathrm{~cm}^{-1}$ region can be clearly seen to contribute to the observed pattern.

Physical deformation of ilmenite inclusions were also observed in both M441/001 and M572/001 with common examples of mosaic fractures present to varying degrees of intensity. Many of these were located close to high concentrations of $\mathrm{FeO}$ rich composites indicating some degree of degradation of the ilmenite crystal had occurred. Figure $6 \mathrm{~d}$ shows one example of the disproportionment of ilmenite into mixed oxides in the rock salt $(\mathrm{FeO})$ and fluorite $\left(\mathrm{TiO}_{2}\right)$ phases as observed by $\mathrm{Liu}^{29}, 1975$, in static recovery experiments $\left(\mathrm{King}^{30}, 1976\right)$. 

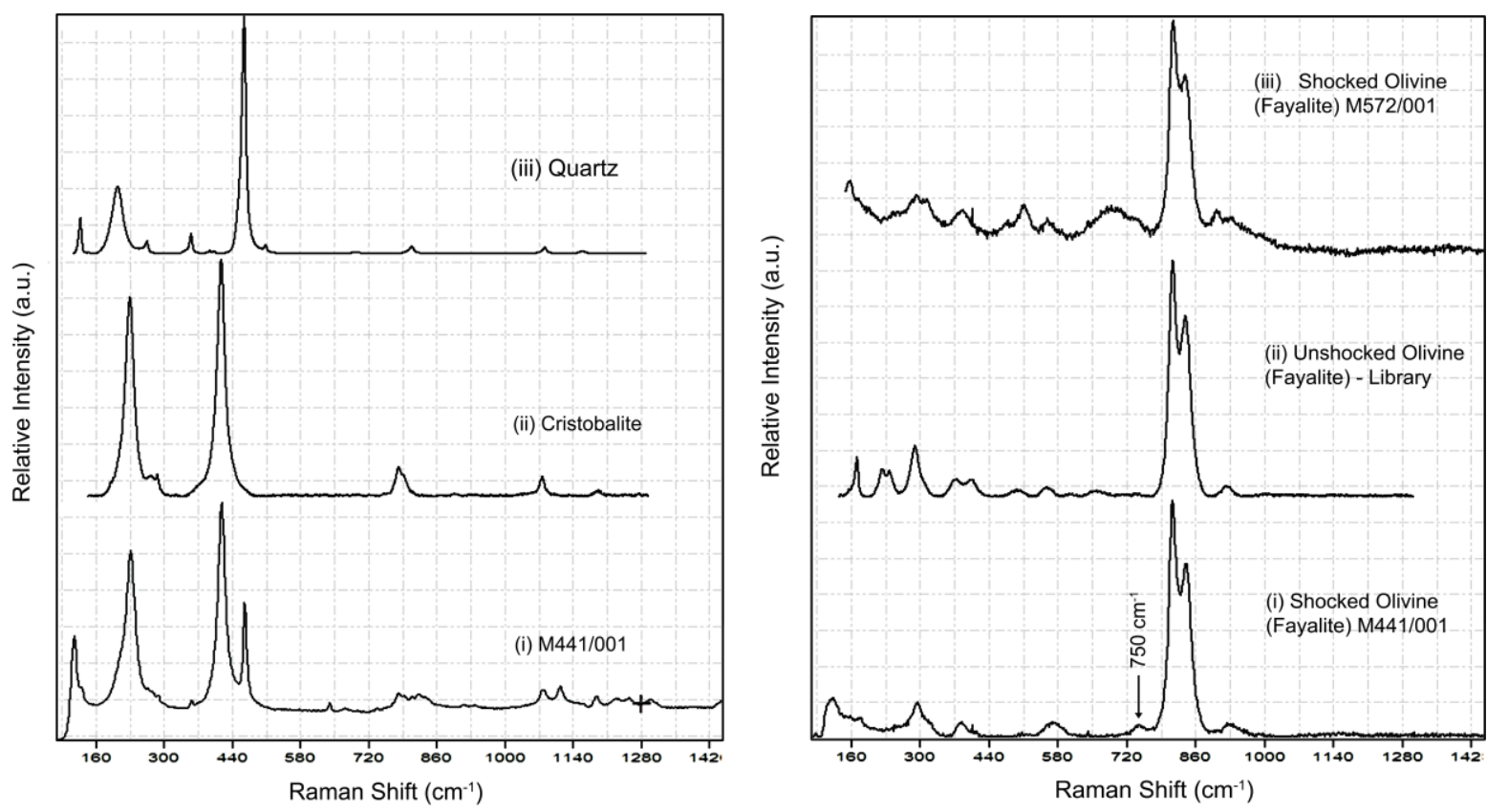

Figure 7 (left panel) shows the high resolution Raman spectra (i) of a typical quartz inclusion in sample M441/001 acquired through a $40 \mathrm{x}$ objective with a beam size occupying approximately $25 \%$ of the crystal's surface area. Library patterns for pure quartz and cristobalite are shown in spectra (iii) and (ii) respectively. Note the contribution to spectra (i) of both primary and secondary features in the $100 \mathrm{~cm}^{-1}$ to $500 \mathrm{~cm}^{-1}$ region in spectra (iii) and (ii) that can be seen to contribute to the observed pattern. All spectra were acquired at the School of Chemistry, Cardiff University, UK using the Renishaw inVia microRaman system.

\section{BULK COMPOSITION}

\subsection{Bulk Minerals}

The presence of crystalline phases was determined using X-Ray Diffraction techniques carried out on a Philips PW1710 Automated Powder Diffractometer on five different aliquot samples of the Polonnaruwa, Ratkinda and Girandanakotte stones. Results are displayed in Figures 8 and 9.

The broad hump displayed in P159/001-03, M224/001-02 and M441/001-02 at $\sim 18-38^{\circ} 2 \theta$ corresponds to a bulk composition of amorphous phases comprising of between $75-95 \%$ by volume. In the case of M224/001-02 no crystalline phases were identifiable with any degree of confidence.

With the exception of M224/001-02, all samples displayed strong features for crystalline quartz, making identification by XRD difficult in the case of high pressure, high temperature polymorphs such as cristobalite and stishovite. Here, prominent features for quartz (Machatschki F ${ }^{31}, 1936$ ) are coincident with cristobalite (Peacor D. R. ${ }^{32}, 1973$ ) and stishovite (Yamanaka T., Fukuda T., Tsuchiya J. ${ }^{33}$, 2002) though a limited number of unique, quite weak features can be identified.

In the case of P159/001-03 the presence of crystalline quartz was confirmed, with intense features at $20.83^{\circ} 2 \theta, 26.71^{\circ} 2 \theta$ and $60.06^{\circ} 2 \theta$ together with numerous lesser features. A strong feature at $\sim 21.82 \theta$ together with weaker coincident features in the 24.3-35.8 $2 \theta$ range was identified as $(\mathrm{NaK}) \mathrm{AlSi}_{3} \mathrm{O}_{8}$ (anorthoclase) (Harlow G. E. ${ }^{34}, 1982$ ). Further peaks at $13.81^{\circ} 2 \theta$ and in the $21.85-35.72^{\circ} 2 \theta$ range were reported as due to the presence of $\mathrm{NaAlSi}_{3} \mathrm{O}_{8}$ (albite) (Gualtieri A. $\left.\mathrm{F}^{35}, 2000\right)$. A further strong peak at $27.82^{\circ} 2 \theta$ together with lesser peaks in the 20.83-35.72 $2 \theta$ range was consistent with the presence of $\mathrm{CaAl}_{2} \mathrm{Si}_{2} \mathrm{O}_{8}$ anorthite (Matsui T. ${ }^{36}$, Kimata $\mathrm{M}^{37}$, 1997). The presence of both cristobalite and stishovite was tentatively confirmed from the residual peaks of the XRD pattern. 

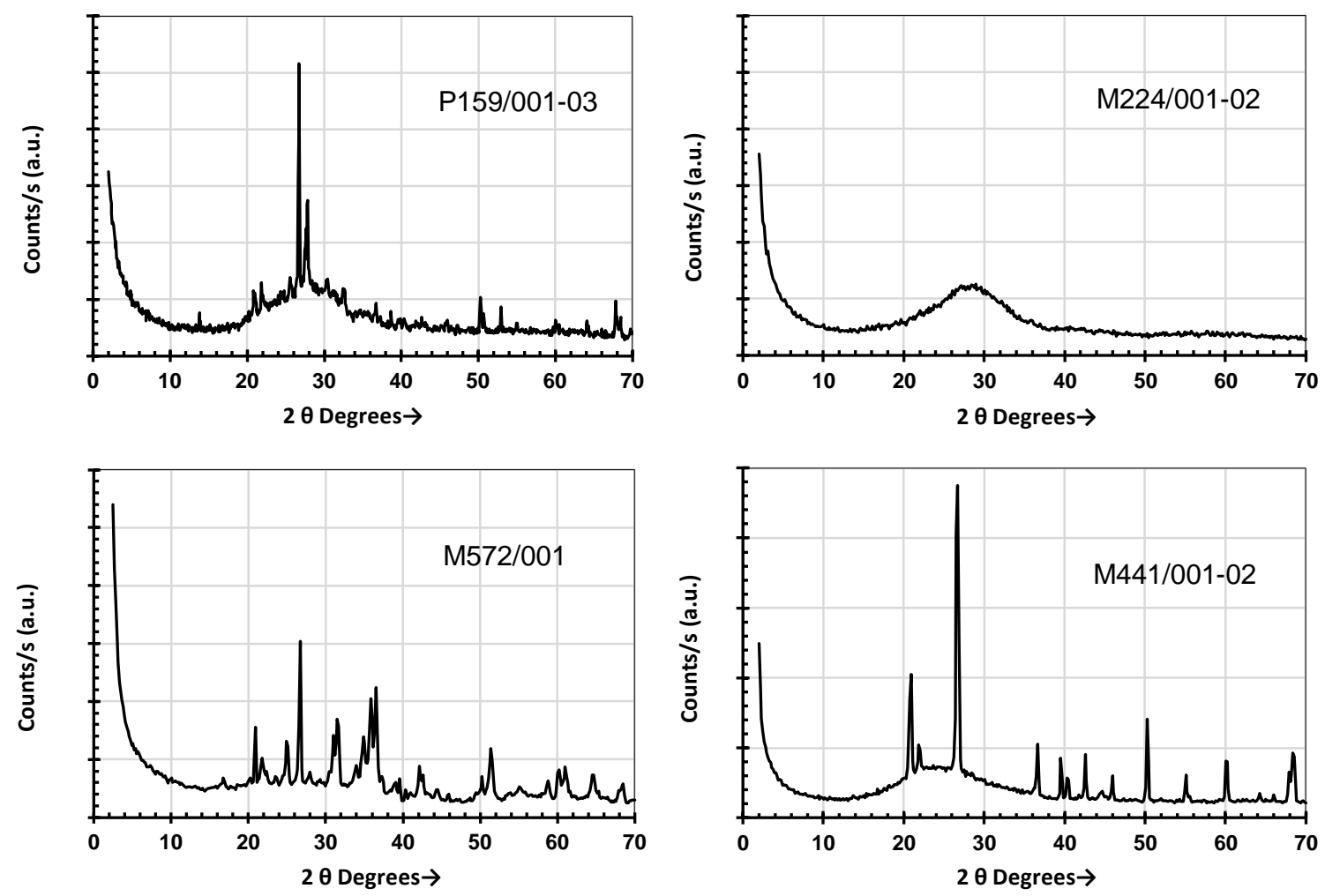

Figure 8: X-Ray Diffraction results (counts/s against $2 \theta$ degrees). Panels show diffractograms of aliquot samples P159/001-03 (upper left), M224/001-02 (upper right), M572/001 (bulk composition) (bottom left) and M441/001-02 (bottom right) using Cu K $\alpha$ radiation at $35 \mathrm{kV}$ and $40 \mathrm{~mA}$, between 2 and $70^{\circ} 2 \theta$ at a scan speed of $0.04^{\circ} 2 \theta / \mathrm{s}$. Analysis software reports the presence of: (i)

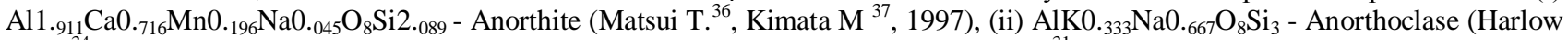
G. E. ${ }^{34}, 1982$ ), (iii) $\mathrm{SiO}_{2}$ - Quartz Lo (Machatschki F, "Kristallstruktur von Tiefquarz ${ }^{31}$, 1936), (iv) $\mathrm{Al1} \cdot{ }_{02} \mathrm{CaO} .{ }_{02} \mathrm{Na}_{0.98} \mathrm{O}_{8} \mathrm{Si} 2 .{ }_{98}-$ Albite (Gualtieri A. F. ${ }^{35}$, 2000), (v) $\mathrm{SiO}_{2}$ - Cristobalite (Peacor D. R. ${ }^{32}$, 1973), (vi) $\mathrm{SiO}_{2}$ - Stishovite (Yamanaka T., Fukuda T., Tsuchiya J. ${ }^{33}$, 2002). The broad humps displayed in samples P159/001-03, M224/001-02 and P441/001-02 are due to bulk composition of amorphous phases of (between 75-100\%).

S159/001-05 (soil) reported the expected presence of approximately 75\% quartz, $17 \% \mathrm{KAlSi}_{3} \mathrm{O}_{8}$ (microcline), $4 \%$ (NaK)AlSi $\mathrm{O}_{8}, 3 \% \mathrm{Al}_{2} \mathrm{Si}_{2} \mathrm{O}_{5}(\mathrm{OH})_{4}$ (kaolinite) and 1\% opal. Results reported for the control sample D159/001-01 were consisted with the available literature on soil carbonates comprising of $81 \%$ calcite, $13 \%$ quartz, $4 \%$ ankerite and $2 \%$ anorthite.

Much like P159/001-03, sample M441/001-02 displayed strong features at $20.98^{\circ} 2 \theta, 26.78^{\circ} 2 \theta, 36.72^{\circ} 2 \theta$ and $68.54^{\circ} 2 \theta$ which together with lesser features at $\sim 68^{\circ} 2 \theta$ confirmed the presence of crystalline quartz. Here however, additional features not usually displayed by quartz and more commonly associated with cristobalite were also detected $\left(22.93^{\circ} 2 \theta\right.$, $23.25^{\circ} 2 \theta, 23.77^{\circ} 2 \theta$ and $25.69^{\circ}$ ) (Dove, $\mathrm{T}^{38}, 2000$ ). Semi-quantative analysis suggests the presence of cristobalite in a ratio of approximately 7:1 in favour of quartz. Additional crystalline phases were suggested by the analytical software but none of these could be confirmed with any degree of confidence.

Results for M572/001 are presented for the bulk material in Figure 7 (lower left panel) and for two slightly differing lithologies in Figure 8 (upper left and right panels). In the case of M572/001-05, the presence of crystalline quartz was confirmed with characteristic features at $20.95^{\circ} 2 \theta, 26.72^{\circ} 2 \theta, 36.64^{\circ} 2 \theta, 40.44^{\circ} 2 \theta, 42.63^{\circ} 2 \theta, 45.93^{\circ} 2 \theta, 60.15^{\circ} 2 \theta$ and $60.15^{\circ} 2 \theta$. Similarly, cristobalite was strongly inferred from the presence of peaks at $21.82^{\circ} 2 \theta, 31.07^{\circ} 2 \theta$ and $35.95^{\circ} 2 \theta$ with weaker coincident peaks identified at $27.97^{\circ} 2 \theta, 44.60^{\circ} 2 \theta$ and $48.49^{\circ} 2 \theta . \mathrm{CaAl}_{2} \mathrm{Si}_{2} \mathrm{O}_{8}$ (anorthite) was also reported 

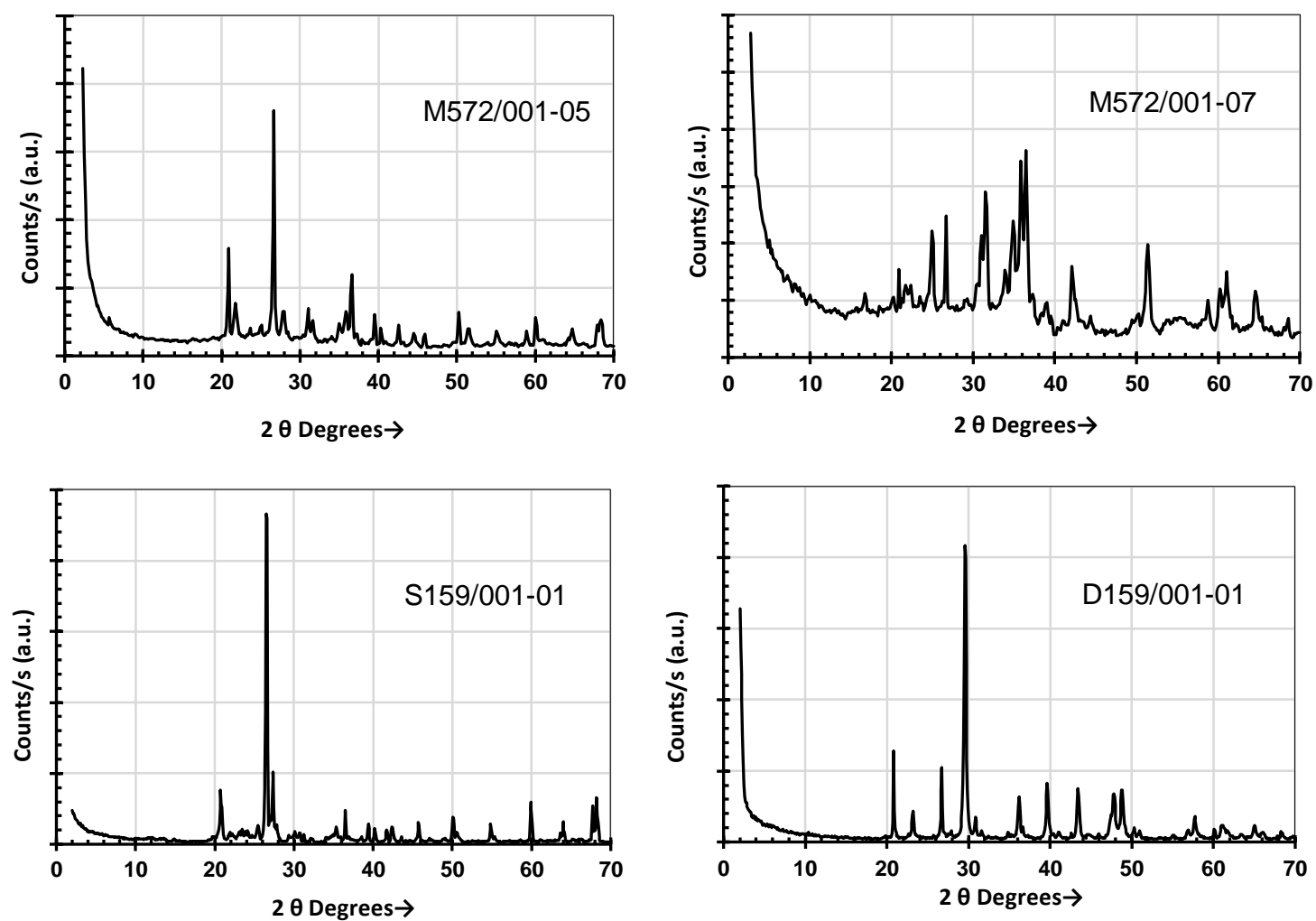

Figure 9: X-Ray Diffraction results (counts/s against $2 \theta$ degrees). Panels show diffractograms of aliquot samples M572/001-05 (upper left), M572/001-07 (upper right), S159/001-01 (soil sample) (bottom left) and D159/001-0 (control) (bottom right) using Cu Ka radiation at $35 \mathrm{kV}$ and $40 \mathrm{~mA}$, between 2 and $70^{\circ} 2 \theta$ at a scan speed of $0.04^{\circ} 2 \theta / \mathrm{s}$. Analysis software reports in M572/001 the presence

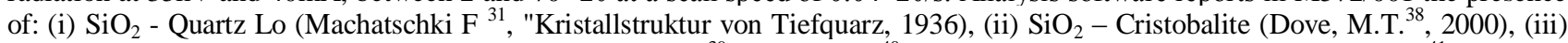

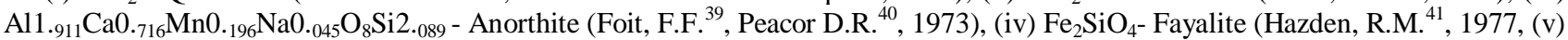
$\mathrm{Fe} 0{ }_{2} \mathrm{Mg} 1_{8} \mathrm{O}_{4} \mathrm{~S}$ - Wadsleyite (Holl C. M. ${ }^{28}$ et al., 2008), (vi) FeO - Wuestite (Wyckoff R. W. G. ${ }^{29}, 1963$ ) and (vi) $\mathrm{FeAl}_{2} \mathrm{O}_{4}-\mathrm{Hercynite}$ (Lavina, B. ${ }^{42}$ et al., 2005).

with a strong coincident feature at $6.89^{\circ} 2 \theta$ and numerous weaker coincident features in the $16.41^{\circ} 2 \theta-32.64^{\circ} 2 \theta$ range (Foit, F. F. ${ }^{39}$, Peacor D. R. $.^{40}, 1973$ ). Further strong coincident features at $31.65^{\circ} 2 \theta, 32.24^{\circ} 2 \theta$ and $51.53^{\circ} 2 \theta$ were identified as olivine (fayalitic $-\mathrm{Fe}_{2} \mathrm{SiO}_{4}$ ) (Hazden, R.M. ${ }^{41}$, 1977) while further strong features at $19.03^{\circ} 2 \theta, 31.07^{\circ} 2 \theta$ and $36.64^{\circ} 2 \theta$ were attributed to $\mathrm{FeAl}_{2} \mathrm{O}_{4}$ (hercynite) (Lavina, B. et al. ${ }^{42}, 2005$ ).

In summary (and taken in isolation) XRD data implies that P159/001 comprises of approximately 85-95\% amorphous glass with trace $(<5 \%)$ quartz, anorthoclase, albite and hematite with the lesser but likely inclusion of cristobalite and stishovite. M224/001 comprises almost entirely of amorphous glass while M441/001 includes a combined ( 10\%) quartz and cristobalite. M572/001 shows inclusions of quartz, olivine (fayalitic), anorthite, cristobalite, hercynite and wadsleyite with an additional presence of wuestite identified in sample M572/001-07.

\subsection{Bulk Chemistry}

Five different samples of the Polonnaruwa, Ratkinda and Girandanakotte stones were analysed for bulk major and trace element abundances using x-ray florescence (XRF) and inductively coupled plasma optical emission spectrometry (ICPOES). These included portions of aliquot samples A, B, C, D and E taken from P159/001, M224/001, M572/001, M441/001 and M572/001 respectively. Representative oxide compositions are given in Table 3. 
Table 3

Average bulk compositions of samples P159/001, M224/001, M572/001 (two samples) and M441/001 together with comparative compositions taken from the literature

\begin{tabular}{|c|c|c|c|c|c|c|c|c|c|c|c|c|}
\hline & \multicolumn{5}{|c|}{$\begin{array}{r}\mathrm{S} 1-\mathrm{M} 572 / 001-05, \mathrm{~S} 2-\mathrm{M} 572 / 001-08 \\
\mathrm{~S} 3-\mathrm{M} 441 / 001, \mathrm{~S} 4-\mathrm{P} 159 / 001 \\
\mathrm{~S} 5-\mathrm{M} 224 / 001\end{array}$} & \multicolumn{3}{|c|}{$\begin{array}{r}\text { S6 - Fusion Crust MIL } \\
\text { 05035, S7 Bulk Recon, } \\
\text { S8 - Bulk Rock }\end{array}$} & \multicolumn{4}{|c|}{$\begin{array}{r}\text { S9, S10 - Core and rim of Mafic glass } \\
\text { (NWA 1664), S11, S12 - High K/Low } \\
\text { K Felsic Glass }\end{array}$} \\
\hline & S1 & $\mathrm{S} 2$ & S3 & S4 & S5 & S6 & S7 & S8 & S9 & S10 & S11 & S12 \\
\hline $\mathrm{SiO}_{2}$ & 49.74 & 49.42 & 51.34 & 60.65 & 65.46 & 45.50 & 47.0 & 48.4 & 51.10 & 49.82 & 66.41 & 65.36 \\
\hline $\mathrm{Al}_{2} \mathrm{O}_{3}$ & 11.90 & 16.82 & 13.23 & 0.00 & 0.19 & 9.61 & 9.26 & 8.85 & 13.38 & 13.17 & 17.87 & 18.96 \\
\hline $\mathrm{Na}_{2} \mathrm{O}$ & 1.62 & 1.62 & 3.91 & 0.54 & 0.54 & 0.32 & 0.26 & 0.21 & 0.20 & 1.21 & 0.56 & 0.61 \\
\hline $\mathrm{MgO}$ & 1.39 & 0.60 & 0.99 & 4.97 & 3.98 & 5.83 & 7.44 & 7.79 & 8.34 & 7.72 & 0.21 & 0.19 \\
\hline $\mathrm{K}_{2} \mathrm{O}$ & 7.41 & 1.61 & 6.44 & 22.69 & 22.69 & 0.05 & 0.03 & 0.01 & 1.41 & 0.06 & 5.80 & 3.95 \\
\hline $\mathrm{CaO}$ & 4.34 & 1.68 & 2.38 & 4.90 & 5.18 & 11.9 & 11.8 & 12.1 & 10.91 & 10.82 & 4.99 & 7.04 \\
\hline $\mathrm{FeO}$ & 12.68 & 12.16 & 5.56 & 0.35 & 0.17 & 22.5 & 22.0 & 20.7 & 13.17 & 15.52 & 1.97 & 1.96 \\
\hline $\mathrm{TiO}_{2}$ & 0.83 & 1.00 & 0.67 & 0.00 & 0.00 & 1.99 & 1.44 & 0.90 & 0.73 & 0.72 & 1.04 & 1.11 \\
\hline $\mathrm{MnO}$ & 1.03 & 0.13 & 0.00 & 1.29 & 1.16 & 0.36 & 0.32 & 0.33 & 0.47 & 0.54 & 0.08 & 0.05 \\
\hline $\mathrm{Cr}_{2} \mathrm{O}_{3}$ & na & na & na & na & na & 0.30 & 0.33 & 0.30 & 0.45 & 0.43 & 0.26 & 0.49 \\
\hline $\mathrm{P}_{2} \mathrm{O}_{5}$ & na & na & na & na & na & 0.05 & 0.05 & 0.02 & 0.01 & 0.07 & 0.01 & 0.00 \\
\hline $\mathrm{SO}_{2}$ & na & na & na & na & na & 0.05 & 0.11 & na & na & na & na & na \\
\hline Total & 92.09 & 85.26 & 84.52 & 97.45 & 101.44 & 98.5 & 100 & 99.3 & 100.17 & 100.08 & 99.20 & 99.72 \\
\hline Mg\# & 16.38 & 8.05 & 24.19 & 96.23 & 97.61 & 31.6 & 37.8 & 40.2 & 28.02 & 28.74 & 24.63 & 39.20 \\
\hline
\end{tabular}

Na - not analysed. S1 - M572/001-06, S2 - M572/001-08, S3 - M441/001-03, S4 -P159/001-05, S5 - M224/001-03, S6 - Fusion Crust (MIL 05035) (Thaisen and Lawrence ${ }^{47}, 2009$ ), S7 - Bulk rock composition of MIL 05035 (Liu et al. ${ }^{48}, 2009$ ), S8 - Bulk rock composition of MIL 05035 (Joy et al. $\left.{ }^{49}, 2009\right)$, S9/S10 - NWA 1664 Core and Rim mafic glass (Barrat et al. ${ }^{43}, 2009$ ) S11/S12 NWA 1664 High K/low K felsic glass (Barrat et al. ${ }^{43}$, 2009).

Both the major and trace element data for the samples display some degree of spatial variation in composition, primarily in those elements that concentrate in metal. This certainly reflects an inhomogeneous distribution of these phases, and the data above represents the average of multiple ICP-OES sample runs. Nonetheless, the somewhat heterogeneous nature of the samples justifies a wider sampling process in future studies. In general, however, all samples were characterized by high K compositions, particularly in samples P159/001 and M224/001. In contrast, Fe content was comparable in samples M572/001 and M441/001 with those reported in the core and rim of mafic glass spherules located in NWA 1664 (Barrat et al. ${ }^{43}, 2009$ ), while a marked depletion in Fe content in neighbouring high and low potassium felsic glasses in the same sample appeared to be reflected in the compositions of P159/001 and M224/001. These samples also displayed a marked depletion in $\mathrm{Ti}$ in comparison to M572/001, M441/001 and the reported literature, suggesting the loss of ilmenite during thermal alteration.

Further evidence for shock formation can be found by comparing $\mathrm{FeO}, \mathrm{SiO}_{2}, \mathrm{TiO}_{2}, \mathrm{Al}_{2} \mathrm{O}_{3}$ and $\mathrm{Na}_{2} \mathrm{O}$ sample compositions with those of know impact glasses. Zeigler et al. ${ }^{44}, 2006$ examined the major element compositions of 280 mafic glasses (>10 wt\% FeO) from six different Apollo 16 soil samples that were formed through impact melting or pyroclastic eruption. Five of the six classes of glass examined were determined to have an impact origin as determined by the presence of metal with meteoritic Fe:Ni ratios ( 94:6) within the glass fragments, the volatilisation of alkali elements and that their composition was dissimilar to previously recognized eruptive lunar samples. These included classes of Low-Ti Basaltic, High-Ti Basaltic, High-Al Basaltic, Basaltic Andesite, KREEP and Felspathic Lunar materials. Only one class - the Green Glass Beads - had an obvious eruptive origin (Delano ${ }^{45}$, 1986: Shearer and Papike $\left.^{46}, 1993\right)$.

Figure 10 shows two-element discrimination diagrams of $\mathrm{FeO}$ vs $\mathrm{SiO}_{2}, \mathrm{FeO}$ vs $\mathrm{TiO}_{2}, \mathrm{FeO}$ vs $\mathrm{Al}_{2} \mathrm{O}_{3}$ and $\mathrm{FeO}$ vs $\mathrm{Na}_{2} \mathrm{O}$. Data and plots are from Zeigler et al. $^{44} 2006$. Here the differentiation between six main classes of Apollo 16 mafic glasses 

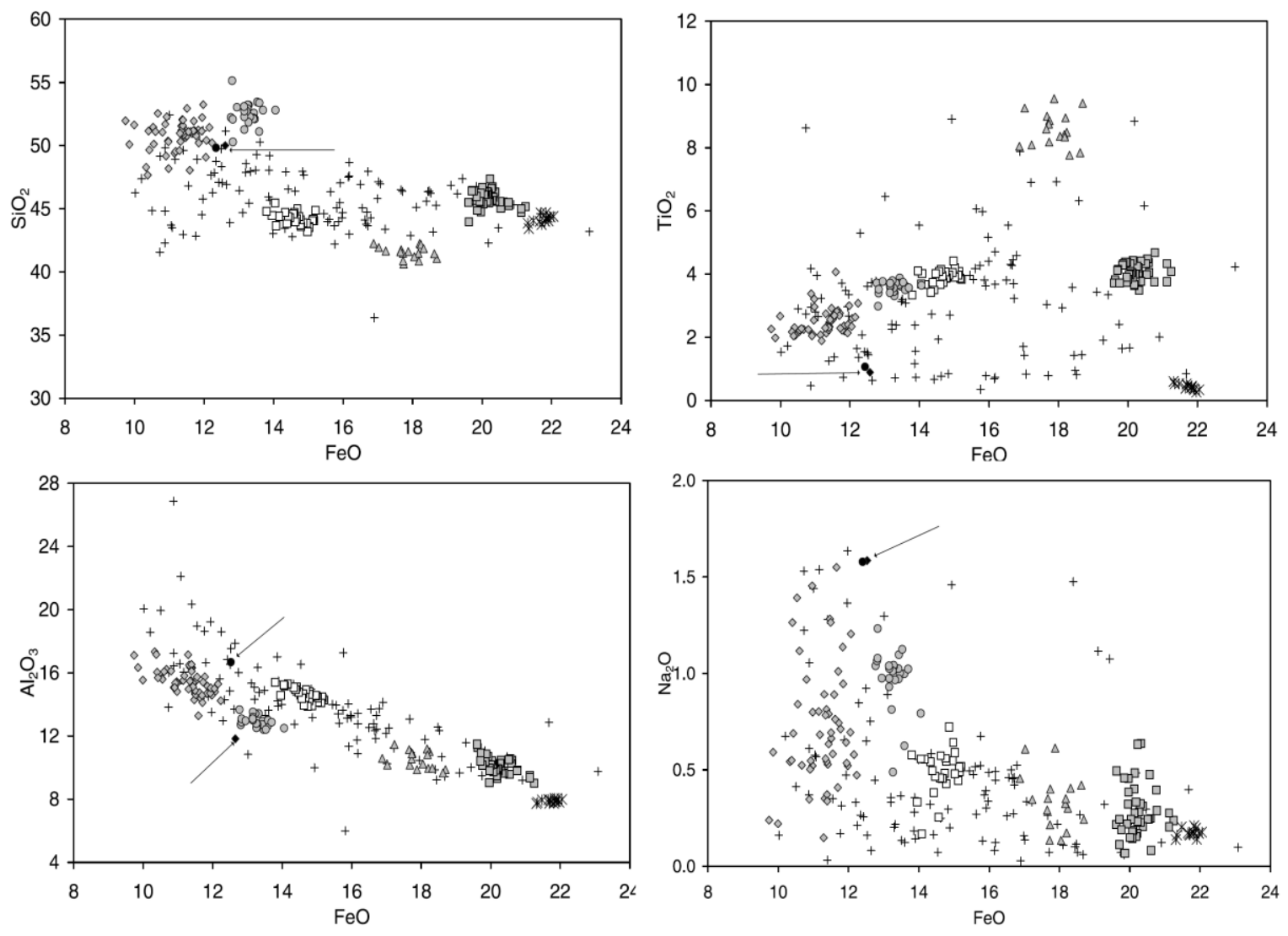

Figure 10: Two-element discrimination diagram differentiating between 6 main classes of non-terrestrial glasses: ' + ' ungrouped, ' $\triangle$ ' High Ti-basaltic, 'X' GGBs, ' $\diamond$ ' KREEP, ' $\square$ ' High Al-basaltic, ' $O$ ' Bas - Andesite, ' $\square$ ' Low Ti basaltic, ' ' M572/001-08 and ' M572/001-05. Plots are for (upper left) $\mathrm{FeO}$ vs $\mathrm{SiO}_{2}$, (upper right) $\mathrm{FeO}$ vs $\mathrm{TiO}_{2}$, (bottom left) $\mathrm{FeO}$ vs $\mathrm{Al}_{2} \mathrm{O}_{3}$ and (bottom right) $\mathrm{FeO}$ vs $\mathrm{Na}_{2} \mathrm{O}$. Data and plots from Zeigler et al. ${ }^{44}, 2006$.

are plotted together with the corresponding values for samples M572/001-05 and M572/001-08. The 'clustering' of the different classes can be clearly observed, with plots for the non-impact generated Green Glass Beads tightly clustered on the periphery of those for the 'impact' glasses. By contrast, samples M572/001-05 and M572/001-08 accord well with those of the impact glasses and remain within relatively close proximity of the KREEP component.

\section{TRACE ELEMENTS}

The increased abundance of Iridium in meteorites when compared to the Earth's crust has been extensively reported in the literature. This is thought to result from the tendency of iridium to bond with iron causing most iridium to have descended below the crust when the planet was young and still molten. Trace element abundances of iridium were determined by ICP-OES in samples P159/001, M224/001, M441/001 and M572/001 together with a sample of terrestrial fulgurite. All samples exhibited high Iridium levels of between 7-8 ppm or approximately $10^{4}$ times average levels reported in oceanic crust. Values for the control fulgurite were below the detectable limits of the apparatus.

Further trace element abundances showed that concentrations of pairs of highly incompatible elements appeared to be strongly correlated in all samples. An example of this can be seen in the Th $(\mu \mathrm{g} / \mathrm{g})$ and $\mathrm{Sm}(\mu \mathrm{g} / \mathrm{g})$ values in sample M572/001, M441/001 and M224/001 where Th/Sm ratios are close to the ratios of CI chondrites. Figure 11 (left panel) shows Th/Sm plots for lunar highlands, lunar mare and lunar KREEP basalts as reported by Korotev ${ }^{50}$ (2005) while Figure 11 (right panel) shows similar plots for $\mathrm{Al}_{2} \mathrm{O}_{3}$ against Th $(\mu \mathrm{g} / \mathrm{g})$. 


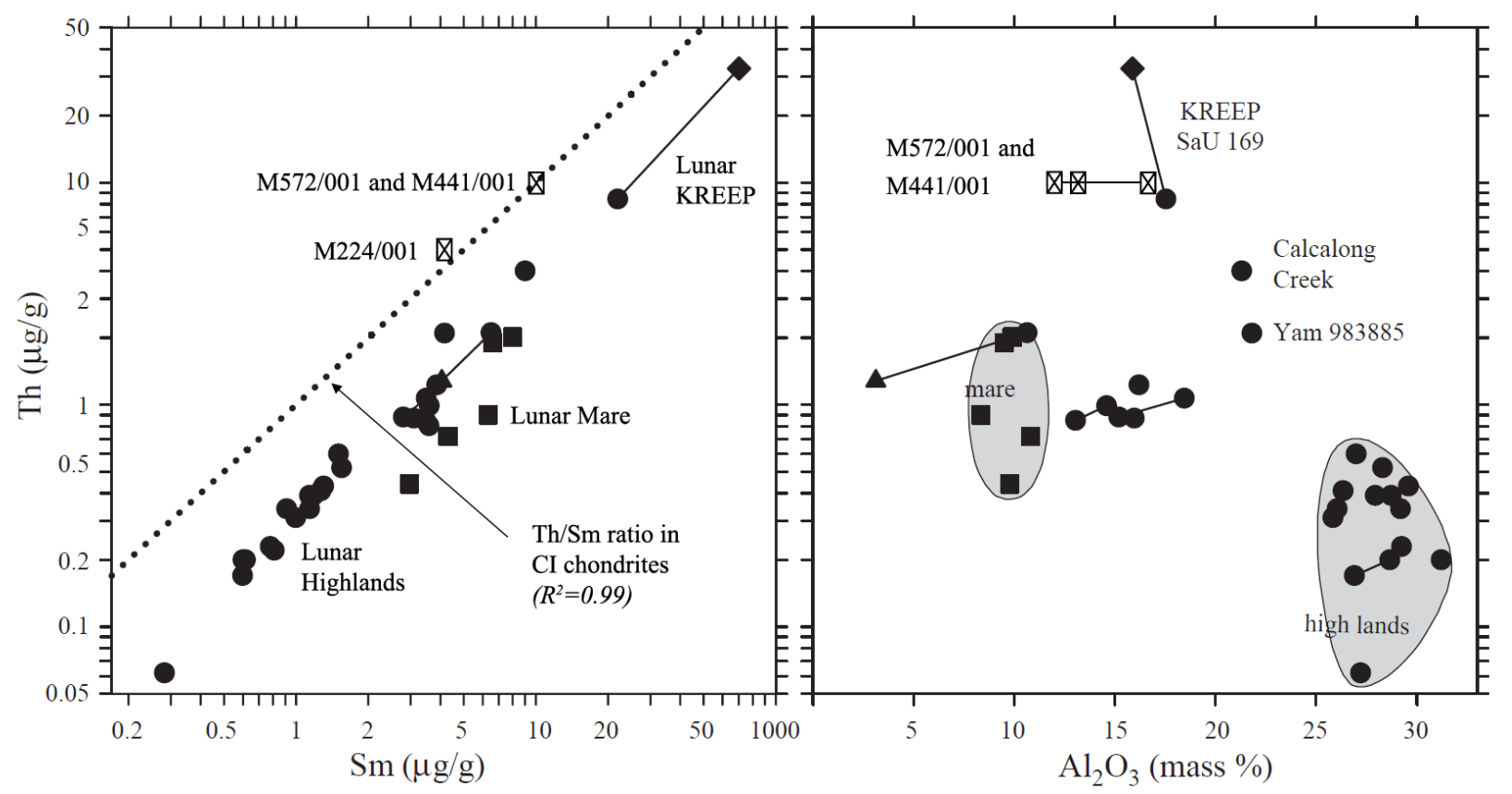

Figure 11: Shows plots of the highly incompatible elements Th and $\mathrm{Sm}$. The dotted line represent the Th/Sm ratio in CI chondrites $\left(R^{2}=0.99\right)$. Plots for Lunar Highlands, Lunar Mare and Lunar KREEP basalts are provided for comparison showing the strong correlation of these basalts off the CI chondrite fractionation trend. Note the position of the plots for M572/001 and M224/001. Data and plots from Korotev ${ }^{50}, 2005$.
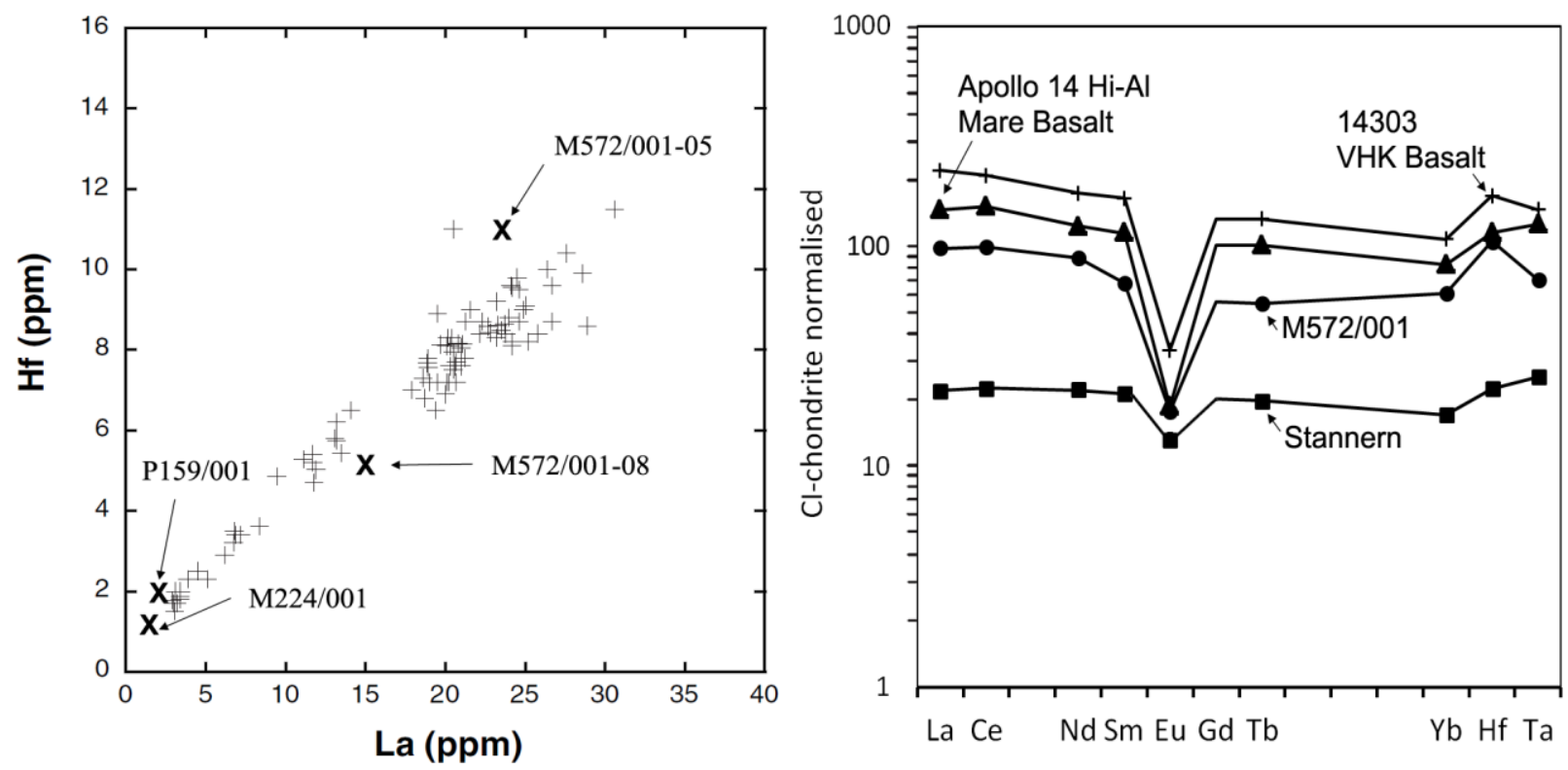

Figure 12: (Left Panel) shows La (ppm) vs Hf (ppm) plots for samples M572/001-05. M572/001-08, P159/001 and M224/001 together with comparable plots for Apollo $14 \mathrm{Hi}-\mathrm{Al}$ basalts from Dickenson et al. ${ }^{51}$ (1985) and Shervais et al. ${ }^{52}$ (1985). (Right Panel) shows CI-chondrite normalised (Greaves and Andres ${ }^{53}$, 1989) REE abundances for M572/001 together with comparable plots for Apollo 14 Hi-Al mare basalts, Very High Potassium (VHK) 14303 basalts and the Stannern Eucrite. Data from Neal and Kramer ${ }^{54}$ (1985), Neal et al. ${ }^{55}$ (1988) and Barret et al. ${ }^{56}$ (2000) respectively. 
Further comparison of La/Hf ratios revealed values broadly consistent with those reported for a range of Apollo 14 highAl basalts (Dickenson et al. ${ }^{51}, 1985$ and Shervais et al. ${ }^{52}, 1985$ ).

Figure 12 (right panel) shows CI-chondrite normalised rare earth element abundances for M572/001 together with comparable plots for Apollo 14 Hi-Al mare basalts, Very High Potassium (VHK) 14303 basalts and the Stannern Eucrite as reported by Neal and Kramer ${ }^{54}$ (1985), Neal et al. ${ }^{55}$ (1988) and Barret et al. ${ }^{56}$ (2000) respectively. Data was normalised using the partition values provided by Greaves and Andres ${ }^{57}$ (1989). The plots show a typical Europium anomaly somewhat anticipated by the bulk composition of the samples and accord well in both trend and abundance with a range of data sets reported in the literature for non-terrestrial materials of similar composition. Again, this data implies some commonality in the formation history of the samples when compared to very high potassium Lunar basalts.

\section{OXYGEN ISOTOPE ANALYSIS}

Results are presented in $\delta$-notation such that: $\left.\delta^{\mathrm{x}} \mathrm{O}_{\mathrm{vSMOw}} / 1000=\left[\left({ }^{\mathrm{x}} \mathrm{O} /{ }^{16} \mathrm{O}\right)_{\text {sample }} /\left({ }^{\mathrm{x}} \mathrm{O} /{ }^{16} \mathrm{O}\right)\right)_{\mathrm{vs} M O w}\right]-1$. We use a slope of 0.5251 for the terrestrial fractionation line and linearized form of the $\delta$-notation so that $\Delta^{17} \mathrm{O}=\delta^{17} \mathrm{O}-0.5251 \delta^{18} \mathrm{O}$. Error has been established through observation of the standard deviation in 290 single analyses of terrestrial rocks and minerals, carried out in 30 sessions at this stable isotope laboratory using the same equipment and is reported as +/$0.06 \%$ (A. Gehler et al. ${ }^{58}, 2011$ ).

Results of analysis show $\Delta^{17} \mathrm{O}=-0.335$ with $\delta^{17} \mathrm{O}=8.978 \pm 0.050$ and $\delta^{18} \mathrm{O}=17.816 \pm 0.100$. Figure 14 shows a plot of $\delta^{17} \mathrm{O} / \delta^{18} \mathrm{O}$ values compared to those of known CI chondrites as reported by Clayton and Mayeda ${ }^{59}, 1998$. It is noted that $\delta^{18} \mathrm{O}$ values are relatively high but are within the range of CI and CI-like chondrites (Meta-C).

The effects of oxygen isotopic exchange during terrestrial atmospheric entry have been examined in part by the STONE experiment. Here, samples of terrestrial rock were secured to the surface of the ablative heat shield of a recoverable Foton-12 spacecraft and flown in low earth orbit for in excess of 14 days before atmospheric re-entry and recovery of the capsule (Brack et al. ${ }^{60}, 2002$ ). The conditions experienced by the capsule during re-entry closely mimicked those under which natural meteorites are subjected to on atmospheric entry and were sufficient to melt basalt and silica glass.

The isotopic composition of tropospheric $\mathrm{O}_{2}$ is given by Luz et al.$^{61}$, (1999) as $\Delta^{17} \mathrm{O}=-0.34$ and is characterised by a mass-independently fractionated component derived from stratospheric photochemical processes involving $\mathrm{O}_{2}, \mathrm{O}_{3}$, and $\mathrm{CO}_{2}$. Results of the STONE experiment showed that the silica 'fusion crust' of one (analogue) sample was characterised by a $\Delta^{17} \mathrm{O}=-0.208$ while the corresponding interior exhibited no offset from a terrestrial silicate or oxide. This provides
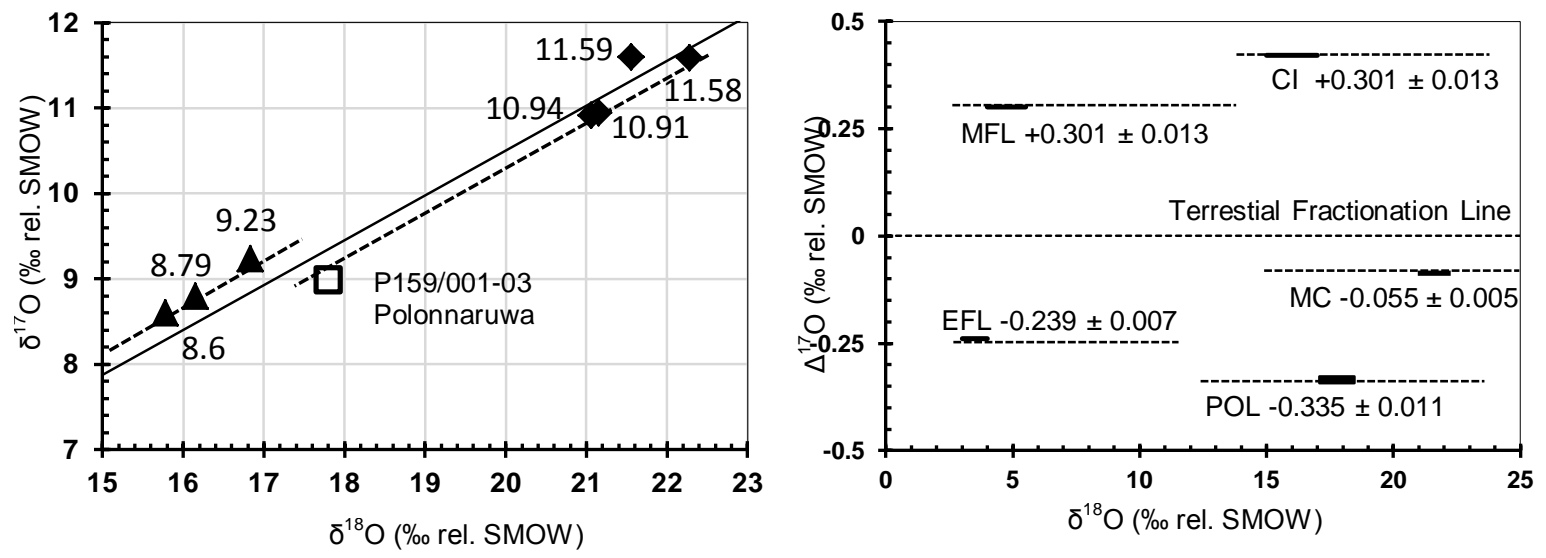

Figure 14. (Left) Oxygen isotope compositions of sample P159/001-04 and of CI chondrites: Alais (8.6), Ivuna (9.23) and Orgueil (8.79) together with CI-like chondrites (Meta-C) B7904 (10.91), Y82162 (11.59), Y86720 (11.58) and Y86789 (10.94). Data from Clayton and Mayeda ${ }^{59}$, 1998. (right) Oxygen isotope $\Delta^{17}$ O (\%o rel. SMOW) values of sample P159/001-04 (POL). Data for MFL: martian fractionation from Franchi et al. ${ }^{62}$, 1999. EFL: eucrite fractionation from Greenwood et al. ${ }^{63}$, 2005. CI: chondrites fractionation and MC: Meta-C (B9704 and Y86789) from Clayton et al. ${ }^{59}, 1998$. 
strong evidence for oxygen isotopic exchange during entry. Furthermore, by taking the carbonaceous interior of the sample holder and tropospheric $\mathrm{O}_{2}$ as end-members, Brack et al ${ }^{60}$, (2002) demonstrated that the silica 'fusion crust' oxygen isotope data fits on a mixing line (regression coefficient $\mathrm{R}^{2}=0.998$ ) with tropospheric $\mathrm{O}_{2}$.

For the purpose of comparison, samples of the well-preserved silica fusion crust and interior of an LL6 ordinary chondrite (Appley Bridge) were similarly analysed. These also exhibited $\Delta \Delta^{17} \mathrm{O}$ variations of comparable magnitude though no apparent change in $\delta^{18} \mathrm{O}$ values were observed. This has been interpretted by Brack et al. ${ }^{60},(2002)$ as implying a more complex isotopic exchange process in the case of this chondrite.

The broad similarity between the $\Delta^{17} \mathrm{O}$ and $\delta^{18} \mathrm{O}$ values of P159/001-04 and tropospheric $\mathrm{O}_{2}$ leads naturally to the question of whether they represent, in part, evidence of some oxygen isotope exchange during entry in the upper atmosphere. P159/001-04 comprised of three interior fragments and dust weighing a combined 2.41g taken from the interior of sample P159/001 while the isotope values exhibited in the Brack et al. ${ }^{60}$, (2002) study comprised of "fusion crust'. In recovered meteorite fragments, the fusion crust is normally quite thin in comparison to the $5 \mathrm{~mm}$ depth from which P159/001-04 was extracted. However, the 'fusion crust' glass in the STONE experiments was noted to approximate that of the pre-flight stones, but were characterised by enrichment in $\mathrm{SiO}_{2}$ (48.1 to $51.9 \mathrm{wt} \%$ ), $\mathrm{CaO}$ (16.7$17.6 \% \mathrm{wt} \%$ ) and $\mathrm{K}_{2} \mathrm{O}$ (1.6 to $2.2 \mathrm{wt} \%$ ) yet depleted in $\mathrm{TiO}_{2}$ (2.1 to $\left.3.8 \mathrm{wt} \%\right) \mathrm{FeO}$ (5.2 to $9.1 \mathrm{wt} \%$ ) and $\mathrm{MgO}$ (3.5 to 4.8 wt\%) which broadly accord with the oxide compositions of some of our samples.

One possible explanation for this could be related to heating of the host material by super-heated gas that pervaded the pore spaces. This mechanism was identified in the STONE experiments as a likely cause for the melting of basalt fragments within the substrate below the fusion crust and deep within the regolith sample.

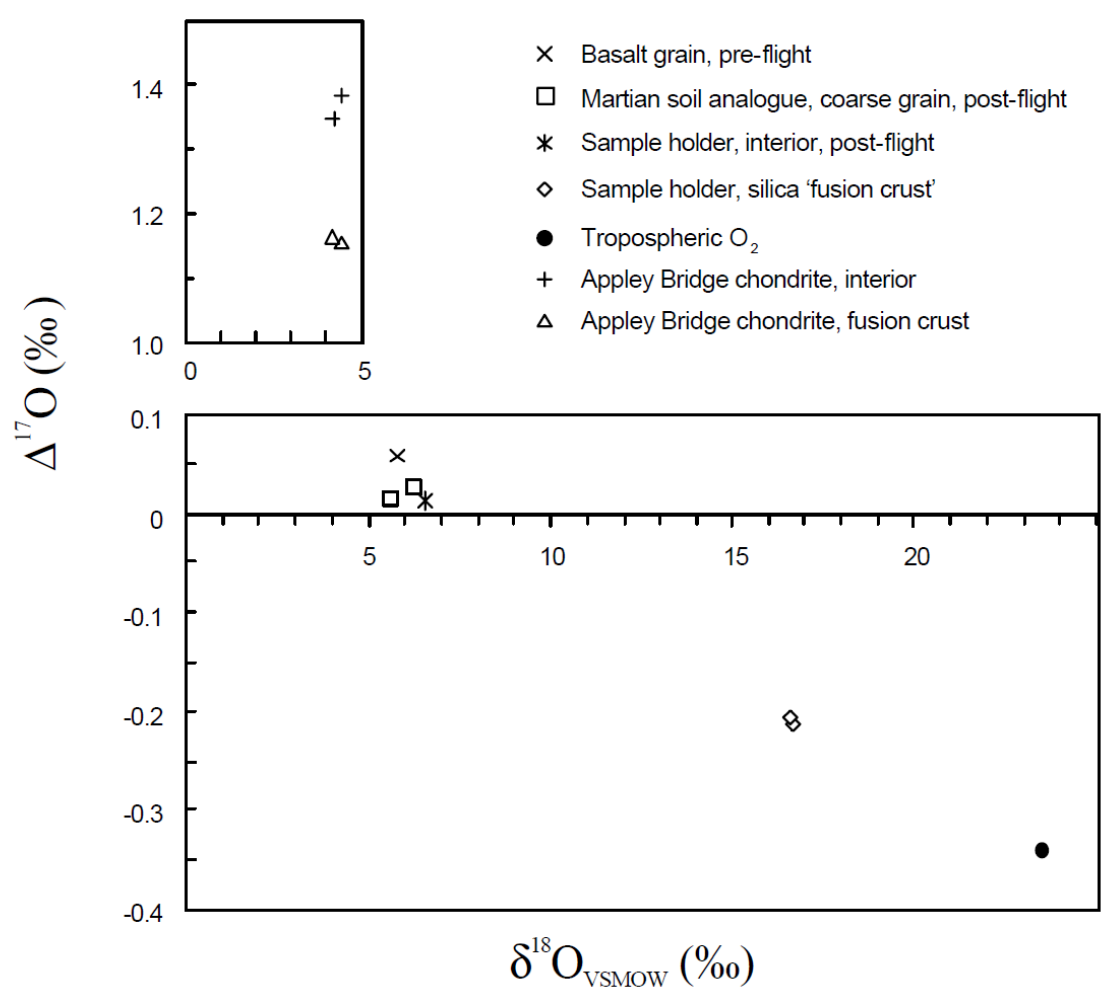

Figure 15. Shows oxygen isotope $\Delta^{17} \mathrm{O}$ (\% rel. SMOW) values for 'STONE' samples together with corresponding values for tropospheric $\mathrm{O}_{2}$ and the fusion crust and interior of the Appley Bridge L6 chondrite. Note that the material lies on a mixing line defined by tropospheric $\mathrm{O}_{2}$ and the carbonaceous interior of the sample holder. Figure and data taken from Brack et al. ${ }^{60}, 2002$. 


\section{DISCUSSION}

The working hypothesis at present is that the more porous $\mathrm{K}-\mathrm{SiO}_{2}$ rich Polonnaruwa and Ratkinda stones represent the ablated mass fraction of the heavier and slightly denser Girandanakotte stones that were recovered approximately $35 \mathrm{~km}$ further along the NE to SW flight trajectory. This is supported by higher $\mathrm{SiO}_{2}$ and $\mathrm{K}_{2} \mathrm{O}$ compositions and lower $\mathrm{TiO}_{2}$, $\mathrm{FeO}$ and $\mathrm{MgO}$ values. Furthermore, the broad similarity between the $\Delta^{17} \mathrm{O}$ and $\delta^{18} \mathrm{O}$ values in these samples with tropospheric $\mathrm{O}_{2}$ suggests some level of oxygen isotope exchange may have occurred during entry in the upper atmosphere. If this is indeed correct, then $\Delta^{17} \mathrm{O}$ values for the parent body may diverge further from the terrestrial fractionation line while $\delta^{18} \mathrm{O}$ values may be significantly less.

In this scenario, pore spaces within the bolide matrix would have been pervaded by super-heated gas on atmospheric entry of the bolide, resulting in the ablation and dissociation of the outer mantle. It is noted that recent modelling by Coulson et al. ${ }^{64}$, (in review) suggests the survivability of highly porous meteoroids may not be particularly dependent on tensile strength. On this note, the recently recovered Maribo meteorite that fell in Denmark on January 17, 2009 had a relatively high entry velocity of $28.5 \mathrm{~km} \mathrm{~s}^{-1}$ and has been linked to the Taurids (Haack et al. ${ }^{65}, 2011$ ). When recovered, the weak $25 \mathrm{~g}$ fragment appeared in tact but fell into many pieces when touched (Haack et al $\left.{ }^{65}, 2012\right)$. The fragment has now been classified as a CM2 carbonaceous chondrite, a group that exhibits one of the highest porosities of all known meteorites at about $15-20 \%$ (Britt and Consolmagno ${ }^{66}, 2003$ ).

On this basis alone the Polonnaruwa, Ratkinda and Girandanakotte stones may be said to represent a new class of meteorite. However, bulk chemical compositions, trace elemental abundances, mineral compositions and petrographic features all point to significant similarities with material of known non-terrestrial provenance. In the meantime, the presence of converted plagioclase feldspar to maskelynite, the presence of several high pressure/temperature polymorphs of olivine and $\mathrm{SiO}_{2}$, the observed high pressure disassociation of ilmenite into mixed oxides, the oxygen isotope compositions and the REE patterns all demonstrate the undeniably meteoritic origin of these stones.

\section{REFERENCES}

1. Saikia B.J., Parthasarathy G., Sarmah N. C., and Baruah G.D. "Fourier-transform infrared spectroscopic characterisation of naturally occurring glassy fulgurites" Bull Mater. Sci. Vol 31 No 2 155-158 (2008)

2. A. El Goresy, B. Wopenka, M. Chen, S. Weinbruch, T. Sharp, Evidence for two di ierent shock induced high pressure events and alkali-vapor metasomatism in Peace River and Tenham (L6) chondrites, LPS XXVIII (1997) 329-330.

3. M. Chen, T.G. Sharp, A. El Goresy, B. Wopenka, X. Xie, The majorite-pyropemagnesio wuestite assemblage constraints on the history of shock veins in chondrites, Science 271 (1996) 1570-1573. M. Chen, B. Wopenka, A. El Goresy, T.G. Sharp, The Peace River (L6) chondrite compositions and pressure temperature history, Meteoritics 31 (1996) A27.

4. Cerling, T. E., and Quade, J., 1993, Stable Carbon and Oxygen Isotopes in Soil Carbonates, In P.K. Swart, K.C. Lohmann, J.A.McKenzie, and S.M.Savin, eds., Climate Change in Continental Isotope Records, pp217-231.

5. Pack, A., 2008, Fractionation of refractory lithophile elements in bulk chondrites and chondrite components. Lunar and Planetary Science Conference, Houston.

6. Mareels, J., 2004. ICP-MS analysis, geochemistry, and petrogenesis of granites from the Variscan Northern Vosges (France). Unpublished PhD thesis, Katholieke Universiteit Leuven, 360 pp

7. Mittlefehldt D. W., McCoy T. J., Goodrich C. A., and Kracher A. 1998. Non-chondritic meteorites from asteroidal bodies. In Planetary materials, edited by Papike J. J. Washington, D.C.: Mineralogical Society of America. pp. 4-1-4-195.

8. Ruzicka, A., Hutson, M., Floss, C., Petrology of silicate inclusions in the Sombrerete ungrouped iron meteorite: Implications for the origins of IIE-type silicate-bearing irons. Meteoritics \& Planetary Science 41, Nr 11, 1797 1831 (2006)

9. Bischoff, A., and Stoffler, D., 1993. Shock metamorphism as a fundamental process in the evolution of planetary bodies: Information from Meteorites. European Jounrnal of Minerology \$ 707-755

10. King, P. L., Dalby, K. D., Russell, S. D. J., Ireland, T., McSween, H. Y., Jr., \& Bischoff, A. 2005, Meteorit. Planet. Sci., 40, A82

11. Sokol, A. K., Bischoff, A., Marhas, K. K., Mezger, K., \& Zinner, E. 2007a, Meteorit. Planet. Sci., 42, 1291 
12. Papike, J.J., Ryder, G., Shearer, C.K., 1998. Lunar Samples. In: Papike, J.J. (Ed.), Reviews in Mineralogy. Planetary Materials, vol. 36. Mineralogical Society of America, Washington pp. 1-5-5-234 (Chapter 5).

13. Papike, J.J., G. Ryder, and C.K. Shearer, Lunar Samples in Rev Mineral., 36, 5-1 to 5-234, 1998

14. Chen, J.H., Papanastassiou D.A., and Wasserburg G.J. 1999 Re-Os and Pd-Ag systematics in Metal rich chondrite Portales Valley (abstract \#1472). 30 $0^{\text {th }}$ Lunar and planetary Science Conf.

15. El Goresy A. et al. (1997), LPSC XXVIII, 329-330

16. Chen M. et al. (1996) Meteoritics, 31, Suppl., A27.

17. Chen M. et al. (1996) Science, 271, 1570.

18. Haloda J., Patricie Tycova, Randy L. Korotev, Vera A. Fernandes, Ray Burgess, Martin Thoni, Monika Jelenc, Petr Jakes, Pavel Gabzdyl, Jan Kosler: Petrology, geochemistry, and age of low-Ti mare-basalt meteorite Northeast Africa 003-A: A possible member of the Apollo 15 mare basaltic suite . Geochimica et Cosmochimica Acta 73 (2009) 3450-3470

19. Ruzicka, A., Hutson, M., Floss, C., Petrology of silicate inclusions in the Sombrerete ungrouped iron meteorite: Implications for the origins of IIE-type silicate-bearing irons. Meteoritics \& Planetary Science 41, Nr 11, 1797 1831 (2006)

20. Zhang, L., W. R. Dawes, G. R. Walker, Water Resour. Res. 37, 701 (2001).

21. Cohen, H. M. and R. Rov (1965) Densification of glass at very high presswe. Phys. Chem. Glasses 6, 149-161.

22. Bunch, T.E., Cohen, J. and Dence, M.R., (1967) Natural Terrestrial Maskelynite. The American Minerologist 52, 244-253

23. Ojima J 2003 J. Occup. Health 4594

24. Parthasarathy G, Kunwar A C and Srinivasan R 2001 Eur. J. Mineral. 13127

25. Schneider H 1974 Contrib. Miner. Petr. 43233

26. Saikia B.J., Parthasarathy G., Sarmah N. C., and Baruah G.D. "Fourier-transform infrared spectroscopic characterisation of naturally occurring glassy fulgurites" Bull Mater. Sci. Vol 31 No 2 155-158 (2008)

27. Gillet, P., J. A. Barrat, E. Deloule, M. Wadhwa, A. Jambon, V. Sautter, B. Devouard, D. Neuville, K. Benzerara, and M. Lesourd (2002), Aqueous alteration in the northwest Africa 817 (NWA 817) Martian meteorite, Earth Planet. Sci. Lett. 203, 431-444.

28. Holl C. M., Smyth J. R., Jacobsen S. D., Frost D. J., "Effects of hydration on the structure and compressibility of wadsleyite, beta-(Mg2SiO4) Locality: synthetic Sample: SS0403, 0.38 wt\% H2O", American Mineralogist 93, 598-607 (2008)

29. Wyckoff R. W. G., "Second edition. Interscience Publishers, New York, New York rocksalt structure", Crystal Structures 1, 85-237 (1963)

30. King, P. L., Dalby, K. D., Russell, S. D. J., Ireland, T., McSween, H. Y., Jr., \& Bischoff, A. 2005, Meteorit. Planet. Sci., 40, A82

31. Machatschki F, "Kristallstruktur von Tiefquarz", Fortschritte der Mineralogie 20, 45-47 (1936)

32. Peacor D. R., "High-temperature single-crystal study of the cristobalite inversion Note: Cell has been corrected Sample: T = 65 C Locality: Ellora Caves, Hyderabad State, India", Zeitschrift fur Kristallographie 138, 274-298 (1973)

33. Yamanaka T., Fukuda T., Tsuchiya J., "Bonding character of SiO2 stishovite under high pressures up to $30 \mathrm{GPa}$ Sample: P = 5.23 GPa", Physics and Chemistry of Minerals 29, 633-641 (2002)

34. Harlow G. E., "The anorthoclase structures: The effects of temperature and composition Grande Caldeira, Or = 32.5, T = 400 deg C feldspar", American Mineralogist 67, 975-996 (1982)

35. Gualtieri A. F., "Accuracy of XRPD QPA using the combined Rietveld-RIR method Locality: Baveno, Novara, Italy", Journal of Applied Crystallography 33, 267-278 (2000)

36. Matsui T., Kimata M., "Crystal chemistry of synthetic Mn-bearing anorthite: Incorporation of MnAl2Si2O8 end-member into feldspar Note: U(1,1) for Obo altered to reproduce Uiso", European Journal of Mineralogy 9 , 333-344 (1997)

37. Kimata, M., (1997) LPSC XXVIII, 329-330

38. Dove M. T., Craig M. S., Keen D. A., Marshall W. G., Redfern S. A. T., Trachenko K. O., Tucker M. G., "Crystal structure of the high-pressure monoclinic phase-II of cristobalite, SiO2 Locality: synthetic Note: P = 3.5 GPa, refinement by constrained Rietveld analysis", Mineralogical Magazine 64, 569-576 (2000)

39. Foit F. F., Peacor D. R., "The anorthite crystal structure at 410 and $830 \mathrm{C} \mathrm{T}=830 \mathrm{C}$ ", American Mineralogist 58, 665-675 (1973) 
40. Peacor D. R., "High-temperature single-crystal study of the cristobalite inversion Note: Cell has been corrected Sample: T = 65 C Locality: Ellora Caves, Hyderabad State, India", Zeitschrift fur Kristallographie 138, 274-298.

41. Hazen R. M., "Effects of temperature and pressure on the crystal structure of ferromagnesian olivine T $=600 \mathrm{deg}$ C, P = 1 atm", American Mineralogist 62, 286-295 (1977)

42. Lavina B., Princivalle F., Della Giusta A., "Controlled time-temperature oxidation reaction in a synthetic $\mathrm{Mg}$ hercynite Spinel structure Sample: Annealing temperature and time T $=600$ C, t $=236$ h", Physics and Chemistry of Minerals 32, 83-88 (2005)

43. Barrat, J.A., Zanda, B., Maynier, F., Bollinger, C., Liorzou, C., and Bayon, G., "Geochemistry of CI chondrites: Major and trace elements, and Cu and Zn Isotopes" Geochimica et Cosmochimica Acta 83 pp79-92, 2012

44. Zeigler, R.A., Korotev, R.L., Jolliff, B.L., Haskin, L.A., and Floss, C. (2006) The geochemistry and provenance of Apollo 16 mafic glasses. Geochimica et Cosmochimica Acta 70 pp6050-6067 2012

45. Delano J. W.(1986) Prestine Lunar Glasses: criteria, data and implications Proc.LPSC,16,D201-D213.

46. Papike J. J., ed. 1998. Comparative planetary mineralogy: Chemistry of melt-derived pyroxene, feldspar, and olivine. In Planetary materials, edited by Papike J. J. Reviews in mineralogy, vol. 36. Washington, D.C.: Mineralogical Society of America. pp. 7-1-7-11.

47. Chen M. et al. (1996) Science, 271, 1570

48. Liu Y., Floss C., Day J. M. D., Hill E., and Taylor L. A. Forthcoming. Petrogenesis of lunar mare basalt meteorite Miller Range 05035. Geochimica et Cosmochimica Acta.

49. Joy K. H., Anand M., Crawford I. A. and Russell S. S. 2007. Petrography and bulk composition of Miller Range 05035: A new lunar VLT gabbro (abstract \#1867). 38th Lunar and Planetary Science Conference. CD-ROM.

50. Korotev, R. L. Lunar geochemistry as told by lunar meteorites. Chemie der Erde 65 (2005) 297-346

51. Dickinson, T., Taylor, G.J., Keil, K., Schmitt, R.A., Hughes, S.S., and Smith, M.R. (1985) Apollo 14 aluminous mare basalts and their possible relationship to KREEP. Proceedings of the 15th Lunar Science Conference, in Journal of Geophysical Research, 90, C365-C375.

52. Shervais, J.W., Taylor, L.A., and Lindstrom, M.M. (1985) Apollo 14 mare basalts: Petrology and geochemistry of clasts from consortium breccia 14321.

53. Anders, E., Grevesse, N., 1989. Abundances of the elements: Meteoritic and solar. Geochim. Cosmochim.Acta 53, 197-214.

54. Neal and Kramer: Apollo 14 High-Al Basalt Petrogenesis 1535 Proceedings of the 15th Lunar Science Conference, in Journal of Geophysical Research, 90, C375.C395.

55. Neal, C.R., Taylor, L.A., and Lindstrom, M.M. (1988) Apollo 14 mare basalt petrogenesis: Assimilation of KREEP-like components by a fractionating magma. Proceedings of the 18th Lunar Science Conference, 139-153.

56. Chen M. et al. (1996) Science, 271, 1570

57. Anders, E., Grevesse, N., 1989. Abundances of the elements: Meteoritic and solar. Geochim. Cosmochim.Acta 53, 197-214.

58. Gehler, A., Tütken, T., and Pack, A., 2011, Triple oxygen isotope analysis of bioapatite as tracer for diagenetic alteration of bones and teeth, Palaeogeography, Palaeoclimatology, Palaeoecology, Vol 310, 1-2 pp 84-91.

59. Clayton, R. N., and Mayeda, T. K., 1999, Oxygen Isotope Studies of carbonaceous chondrites, Geochimica et Cosmochimica Acta, Vol 63, No 13/14 pp2089-2104.

60. Brack, A., P. Baglioni, G. Borruat, F. Brandstlatter, R. Demets, H.G.M. Edwards, M. Genge , G. Kurat, M.F. Miller, E.M. Newton, C.T. Pillinger, C.-A. Roten, E. W1aschh "Do meteoroids of sedimentary origin survive terrestrial atmospheric entry? The ESA arti'cial meteorite experiment STONE". Planetary and Space Science 50 (2002) $763-772$.

61. Luz B, Barkan E, Bender ML, Thiemens MH, Boering KA. 1999. Triple-isotope composition of atmospheric oxygen as a tracer of biosphere productivity. Nature 400:547-5062. $\quad$ Franchi, I.A., Wright, I.P., Sexton, A.S., and Pillinger, C.T. 1999, The oxygen isotope composition of Earth and Mars, Meteoritics \& Planetary Science 34, pp657-661.

63. Greenwood R.C., Franchi I.A., Jambon A. and Buchanan P.C. (2005) Widespread magma oceans on asteroidal bodies in the early solar system. Nature 435, 916-918.

64. Coulson, S., Max Wallis, Nori Miyake, Jamie Wallis and N. Chandra Wickramasinghe. Dynamics of the Polonnaruwa Meteorite, In Review.

65. Haack H., Grau T., Bischoff A., Horstmann M., Wasson J., Sørensen A., Laubenstein M., Ott U., Palme H., Gellissen M., Greenwood R. C., Pearson V. K., Franchi I. A., Gabelica Z., and Schmitt-Kopplin P. 2012. A new CM fall from Denmark. Meteoritics \& Planetary Science 47:30-50.66. Britt and Consolmagno, 2003. 